\title{
Building an Informing Business School: A Case Study of USF's Muma College of Business
}

\author{
T. Grandon Gill, Matthew Mullarkey, \\ Joseph E. Mohr, and Moez Limayem \\ University of South Florida, Tampa, FL, USA \\ grandon@usf.edu mmullarkey@usf.edu \\ josephmohr@mail.usf.edu mlimayem@usf.edu
}

\begin{abstract}
As the complexity of a system grows, the challenge of informing the stakeholders of that system grows correspondingly. Nowhere is that challenge more daunting than in business education, where globalization, technological innovation, and increasingly complicated regulations continuously transform the business environment facing graduates and practitioners. Informing science theory proposes that different levels of complexity require different channels if effective informing is to be achieved. The paper first examines how two important sources of complexity-the diversity of clients and the ruggedness of the business landscape - are changing, and how these changes demand vastly more interactive informing channels if impact is to be achieved. Using an exploratory case study methodology, it then takes a detailed look at how one institution - the University of South Florida's Muma College of Business - has introduced a variety of new channels, many of which enable informing flows without necessarily directing them, to adapt to these environmental changes. It then considers both outcomes related to these individual informing channels and college-wide outcomes related to a broad and deep mosaic of informing flows. Finally, it considers the question of the resources required to support these new channels and the relationship between resource acquisition and channel introduction. The proposed framework for looking at business school informing channels can be applied by administrators, faculty members, and key stakeholders in understanding, evaluating, and planning programs and activities supporting informing in a complex environment. Ultimately, the informing business school framework may also provide a means for communicating impact to business school accrediting agencies (such as AACSB).
\end{abstract}

Keywords: informing science, informing system, internships, externships, business education, case studies, research, channel, complexity, rugged landscape, business school, impact.

Material published as part of this publication, either on-line or in print, is copyrighted by the Informing Science Institute. Permission to make digital or paper copy of part or all of these works for personal or classroom use is granted without fee provided that the copies are not made or distributed for profit or commercial advantage AND that copies 1) bear this notice in full and 2) give the full citation on the first page. It is permissible to abstract these works so long as credit is given. To copy in all other cases or to republish or to post on a server or to redistribute to lists requires specific permission and payment of a fee. Contact Publisher@,InformingScience.org to request redistribution permission.

\section{Introduction}

Informing is central to the mission of virtually every educational institution. Recently, however, serious questions are being raised with respect to the impact that higher education is having on its stakeholders (Gill, 2010). In the U.S., high student loan default rates, failure of many students - particularly disadvan- 
taged students - to graduate, the growth in the number of administrators, and the production of expensive research that appears to serve no useful purpose are all symptomatic of these concerns.

Nowhere are these concerns more apparent than in today's business schools. Accrediting agencies, such as $A A C S B$ International, have made impact a top priority in ongoing accreditations (AACSB, 2008, 2015). Institutions must justify their impact on all their key stakeholders: their students, the community of research scholars, and the community of practice. Failure to demonstrate effective informing of even one of these stakeholder communities could lead to probationary status that could endanger the institution's reputation and even its long term survival. The stakes are high, and institutions must adapt their informing activities both to maximize their effectiveness and to ensure that evidence of their effectiveness is acquired.

From an informing science perspective, the challenge of achieving measurable impact is heightened by the changing nature of the environment being experienced by stakeholders. Of particular importance is the underlying complexity of that environment. It has been argued elsewhere (e.g., Gill, 2010) that the business landscape is growing increasingly complex. While environmental complexity has many sources, some of the most important drivers include the following:

1. Globalization: Serves to increase the number of participants, their diversity, and the degree of interdependence between them, as demonstrated by the emergence of elaborate global supply chains.

2. Technology: Creates new alternatives and combination of alternatives, presenting decision-makers with a continuing stream of new choices; information technology (IT) in particular also increases the rate at which we can communicate and react to communications. IT also increases the number of channels through which informing systems can communicate with stakeholders (e.g., online learning).

3. Regulation: Creates more complicated decision scenarios and may disrupt existing patterns of participant behavior.

From a system point of view, the collective effect of these drivers is to increase the number of entities participating in the system, the interdependence between these entities, the rate at which they react to the behavior of other entities, and the impact of changes to external systems. Also argued elsewhere (e.g., Kauffman, 1993), we can predict that systems experiencing these drivers will change in certain ways. Of greatest importance to this paper are the following:

- Their environment will become more rugged. As interdependence between elements of a system grow, the fitness of combinations of attributes becomes increasingly determined by combinations of elements (i.e., interaction effects) as opposed to individual elements (i.e., main effects). This necessarily leads to the emergence of local peaks of fitness, whose number rises with complexity. The practical effect of such ruggedness is that participants in the system will tend to gravitate towards the local peaks and will often find themselves motivated to imitate other participants (Gill, 2012).

- The environment will grow in turbulence. Complex environments tend to exhibit a behavior over time referred to as punctuated equilibrium. This behavior involves periods of order interspersed with unpredictable, and often quite significant, disruptions. From the participant's perspective, increasing complexity demands increasing adaptability (Gill, 2010).

For the remainder of the paper, we take the growing complexity of the business environment as a given. We now turn to the implications of such growing complexity. First, we introduce the theoretical foundation that informing science has developed for understanding informing under conditions of complexity. This theory is incorporated into a conceptual framework that can be specifi- 
cally applied to a business school and its stakeholders. We then look specifically at important activities and programs introduced by the University of South Florida's (USF) Muma College of Business (MCOB) over the past five years, illustrating how they map to the conceptual framework. In doing so, we note the substantial increase in interactive informing channels associated with these activities. Finally, we consider the observed outcomes and potential implications with respect to resources associated with expanded informing patterns.

\section{Complexity and Informing}

In framing the challenge of informing under conditions of complexity, we adopt a conceptual scheme that has been previously used to describe complex informing systems (e.g., Murphy, Murphy, Buettner, \& Gill, 2015). The model treats the informing process in terms of a movement between fitness states over time, as illustrated in Figure 1. The model treats the informing process as a movement between knowledge states, each of which has its own fitness level. It further assumes that a client will only be motivated to leave an existing knowledge state in order to achieve a state a higher fitness - an assumption that is equivalent to Kuhn's (1970) that a paradigm has never been abandoned prior to the formation of a competing paradigm that was better able to describe the phenomena being investigated. The informing model involves three forms of complexity.

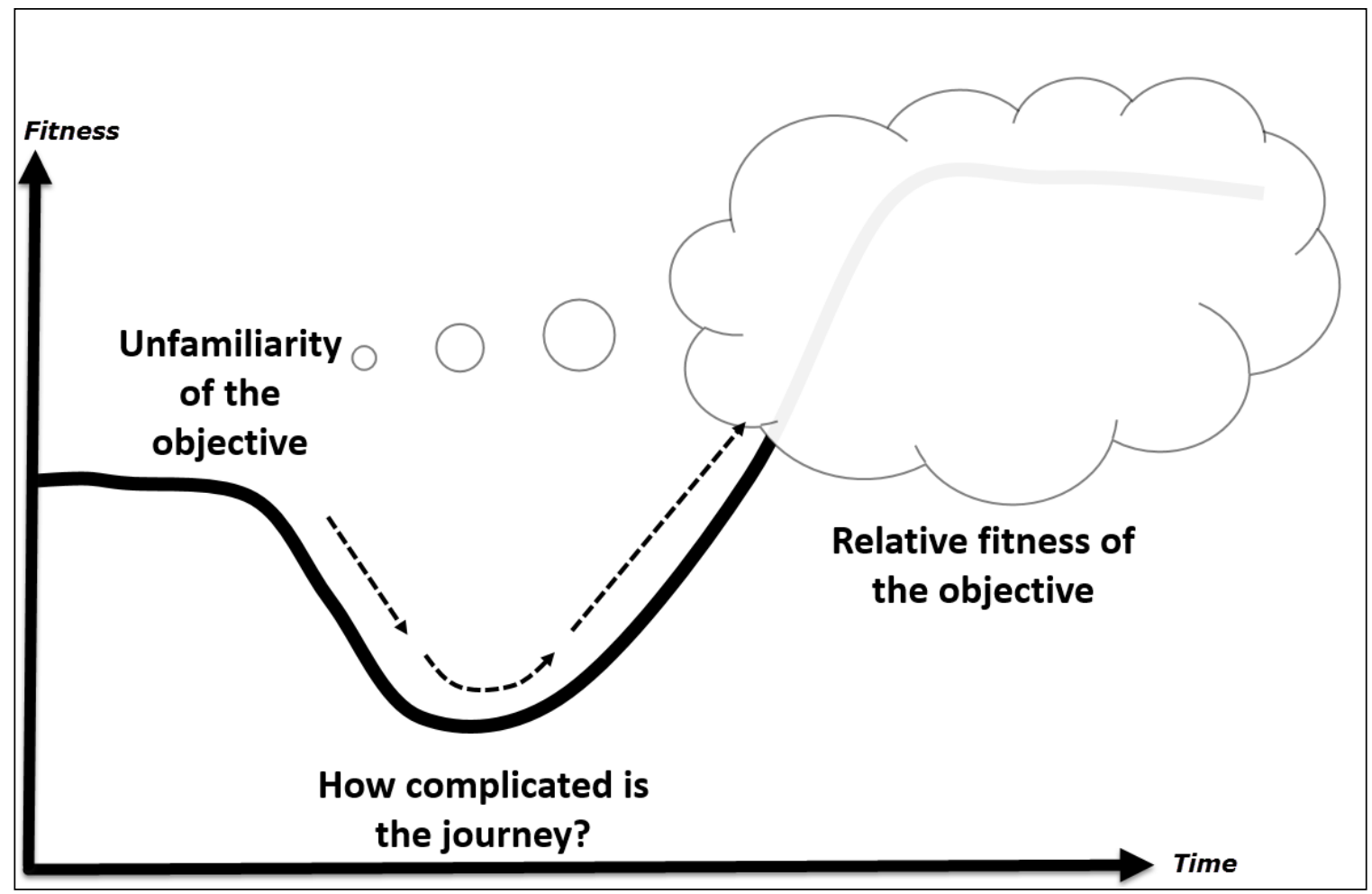

Figure 1. Fitness model of informing

1. Complexity as experienced by the task performer, manifested in the uncertainty and ambiguity associated with the target state and the path from the initial state to the target state.

2. The degree to which the path from initial state to target state is complicated (e.g., requires the acquisition of lots of knowledge and the duration of the period between the abandonment of initial knowledge and the acquisition of the knowledge required to achieve the target state). The ruggedness of the fitness landscape, which increases as the environment 
becomes more complex, tends to increase the depth of the valleys between fitness peaks by increasing the likely penalty of incremental changes from any peak state.

3. The relative fitness of the target vs. the initial state, a difference that must be estimated since actual fitness cannot be known (Gill, 2010).

\section{Growing Environmental Complexity}

In addition to increasing the potential depth of the valleys between fitness peaks, increasing environmental complexity increases the number of peaks. This has two impacts: 1) it can increase the number of potential target states, and 2) it can increase the number of initial states where multiple clients are involved. In Figure 2, this could be interpreted as a move from the bottom left quadrant (homogeneous clients, clear target) towards the upper right quadrant (diverse clients, ambiguous target).

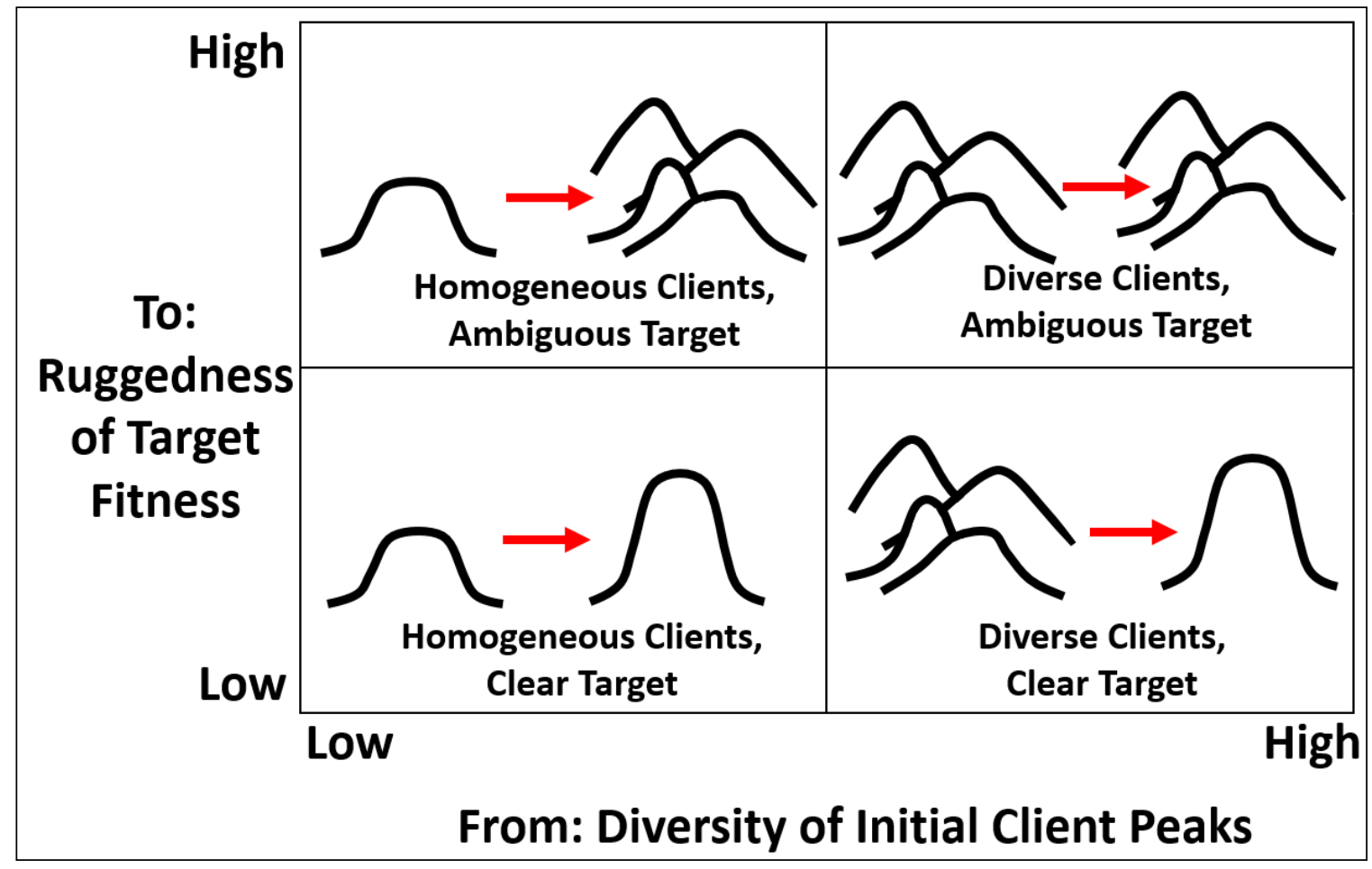

Figure 2: Alternative informing scenarios in the presence of complexity

(Murphy et al., 2015, p. 69)

\section{Growing Participant Diversity}

In the specific context of higher education in the U.S., dramatic changes have taken place in the level of diversity of the client. As an example, in 1970 approximately $11 \%$ of the women in the workforce had a college education or higher; by 2000 , that number had more than tripled to 36.4\% (http://www.bls.gov/opub/ted/2011/ted 20111229.htm).

For a more concrete illustration of the change, consider the photo of a section of the Harvard Business School (HBS) MBA class of 1963, shown in Figure 3, in which the principal observable indicator of diversity appeared to be whether or not the participants wore glasses. According to the HBS website, in that year the first 7 women enrolled (approximately 1\% of a class of 680 ). Purely as an indication of how radically the composition of U.S. business education has changed, this can be contrasted with the HBS MBA class of 2017 , whose composition was $42 \%$ women, 
$28 \%$ U.S. ethnic minorities, and 34\% international. We recognize that demonstrating homogeneity of demographics, such as that of the class of 1963, is a far cry from demonstrating a corresponding uniformity of knowledge state and aspirations. Nevertheless, we believe that it is a reasonable assumption that today's far greater diversity in the student body's composition leads to correspondingly greater diversity in client knowledge states.

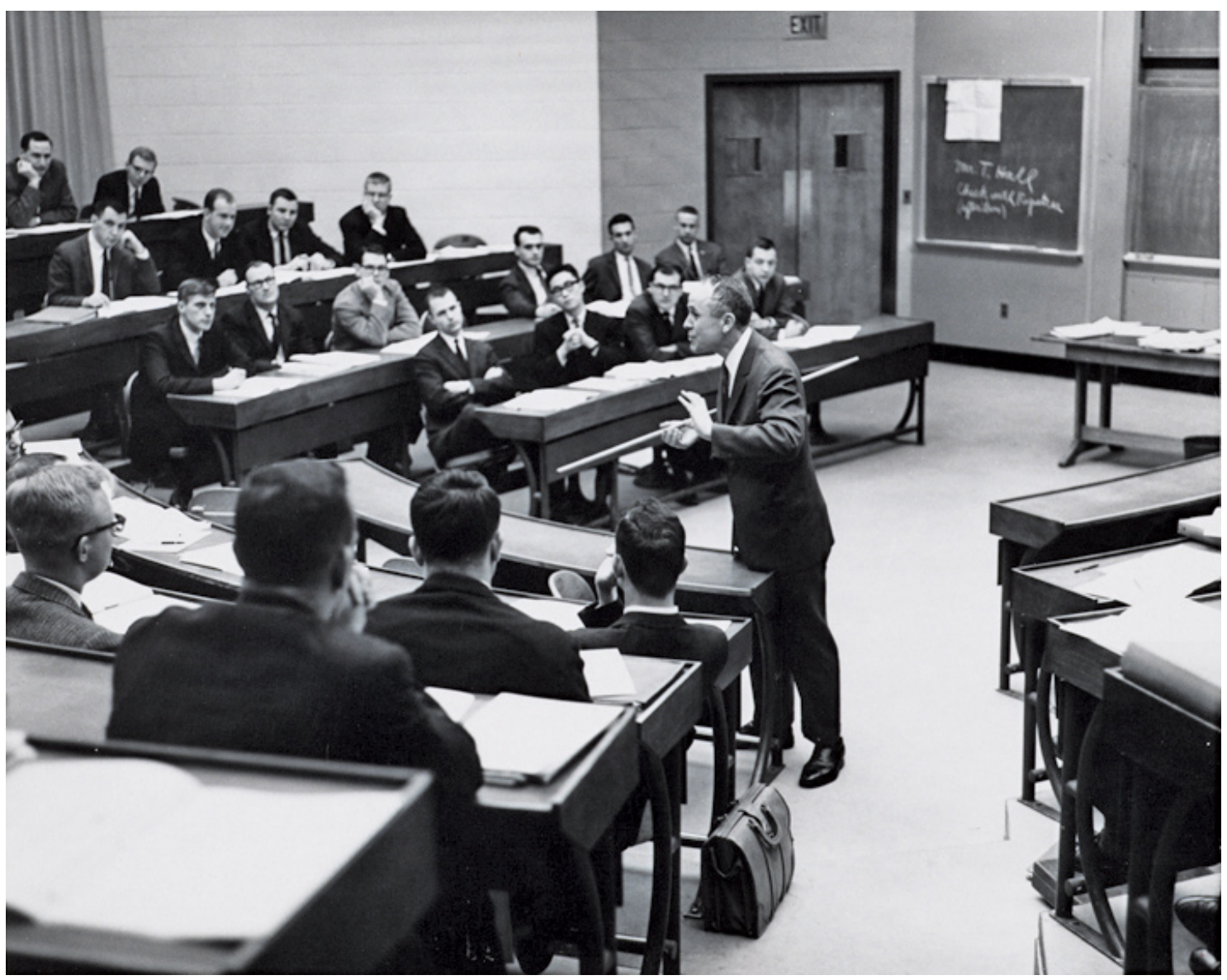

Figure 3. Photo of HBS MBA Class of 1963

From a practical informing standpoint, the increase in the expected number of initial client knowledge states and the increase in the number of potential target states drives the informing context from routine informing to low structure informing, as illustrated in Figure 4.

High structure informing contexts can be adequately handled by one-way communication methods, such as lectures and broadcasts, where the informer guides the client through a pre-planned path to the new knowledge state. As structure declines, however, increasing levels of interaction between informer and client are required if effective informing is to be achieved. In the diverse client/ambiguous target situation, effective informing may be achievable only through a collaboration between informer, client, and the client's peers. Such collaboration is necessary because the number of starting and possible target states creates a proliferation of possible informing paths that is too large to map out in advance.

The conclusion proposed by this model is that as the complexity of the environment being studied and the diversity of the clients being informed grow, so grows the need for interactive informing channels. In the context of business education, in particular, this argues for reduced reliance on lectures and traditional knowledge-based testing and increased emphasis on interactive tech- 
niques, such as discussions and simulations, and on the construction of informing channels supporting interactive exchange of information.

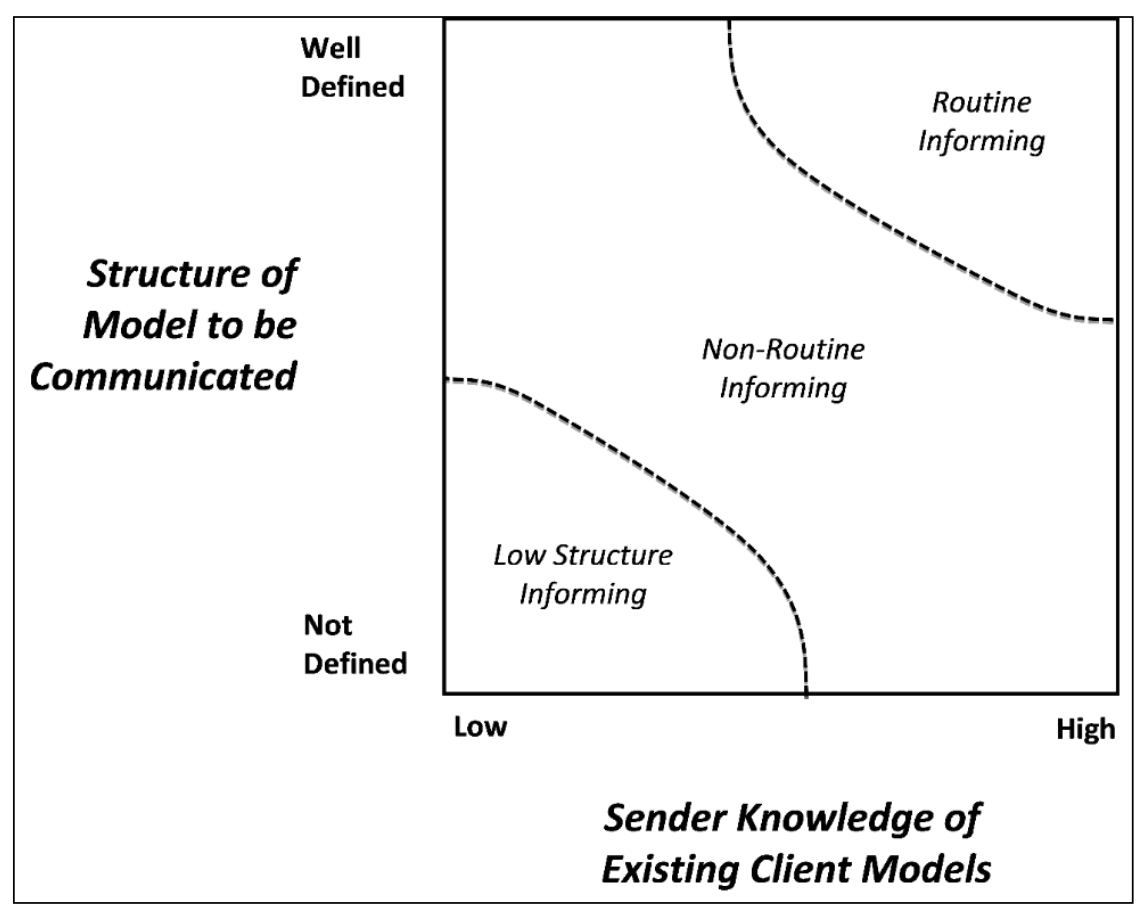

Figure 4. Level of structure in informing process based on structure of knowledge to be communicated and knowledge of pre-existing client models (Gill, 2015a, p. 314).

\section{Business School Informing Paths}

In the previous section, an implicit assumption was made that there was a single category of client - although different client instances could be quite diverse in nature. In fact, a business school has many different categories of stakeholders. The three most important of these are probably students, the research community, and the community of practicing managers that employ the students it graduates. Even simplifying the model by ignoring other stakeholders of undoubted importance - such as the taxpayers for a state funded institution - we find that a business school is likely to participate in many informing channels, as illustrated by Figure 5, the informing flows framework.

The ten paths shown in the informing flows framework (Figure 5) fall into two categories: paths whereby stakeholders are informed directly, and paths where the institutions helps to enable informing pathways without necessarily controlling the informing content. The paths labeled in the figure are as follows:

1. Institution to student: This is the traditional channel through which information flows from the institution (e.g., faculty) to its student clients. The channel may include one-way transmissions, such as lectures and video broadcasts, and may also involve interactions, such as question and answer sessions. A frequently overlooked informing flow in this channel may be the informing flow from the student to the institution (which we explore in several examples in this article).

2. Institution to research: This is the bi-directional channel through which research is disseminated, involving artifacts such as books and papers (one-way channels) and more interactive channels, such as conferences. 


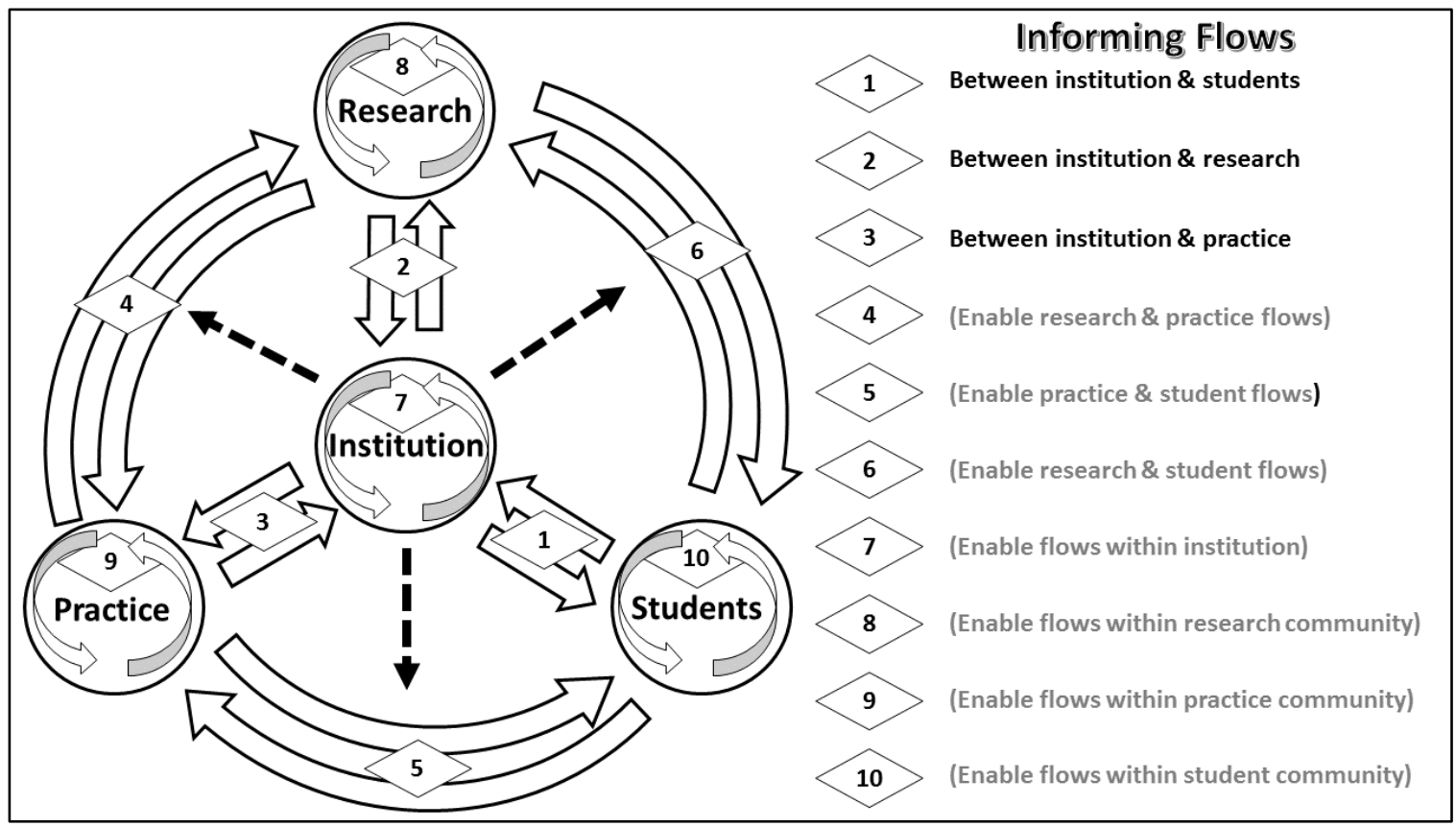

Figure 5. Informing Flows Framework. Examples of potential flows within and between business school stakeholders

3. Institution to practice: This is the bi-directional channel through which the institution directly informs, and is informed by, the business and employer communities that it serves. A two-way interactive channel in this path could be expected to improve the probability that the institution prepares graduates that are desired by practice, involves practice in the identification of research with impact, and improves the institutions ability to attract resources and funding.

4. Research to practice (enabled): This represents a bi-directional channel through which the findings of the research community are communicated to practice and vice versa. An institution might enable such a channel through setting up a venue, such as symposium, in which researchers (not necessarily from the institution itself) and practitioners mingle.

5. Practice to students (enabled): A bi-directional channel through which students and practitioners inform each other directly. An institution might enable such a channel through activities such as setting up an internship program.

6. Research to students (enabled): A bi-directional channel allowing direct communication between researchers and students. An example might be including students as participants in a large research grant.

7. Within institution (enabled): While we have presented the institution as a single unit in the diagram, a better characterization of many business schools might be as a collection of departmental silos. Activities or programs that attempt to break down these silos would be examples of within institution channels.

8. Within research (enabled): Similar to within-institution, except the silos tend to be disciplinary rather than departmental. Support for multidisciplinary research channels would be an example of this type of within research channel.

9. Within practice (enabled): Creation of venues where managers from different industries and functions can interact would be an example of this type of channel. 
10. Within students (enabled): Activities that establish venues where diverse groups of students inform each other (on educational materials, employment opportunities, careers, extracurricular activities, and research) would be an example of this type of channel.

\section{"Straw Man" Business School}

To illustrate how the informing flows framework might be applied to complexity, we start by constructing a "straw man" business school, shown in Figure 6. We so name this illustration because it is so pathologically limited in its informing channels that we doubt it could survive in the current environment - if it ever could have survived.

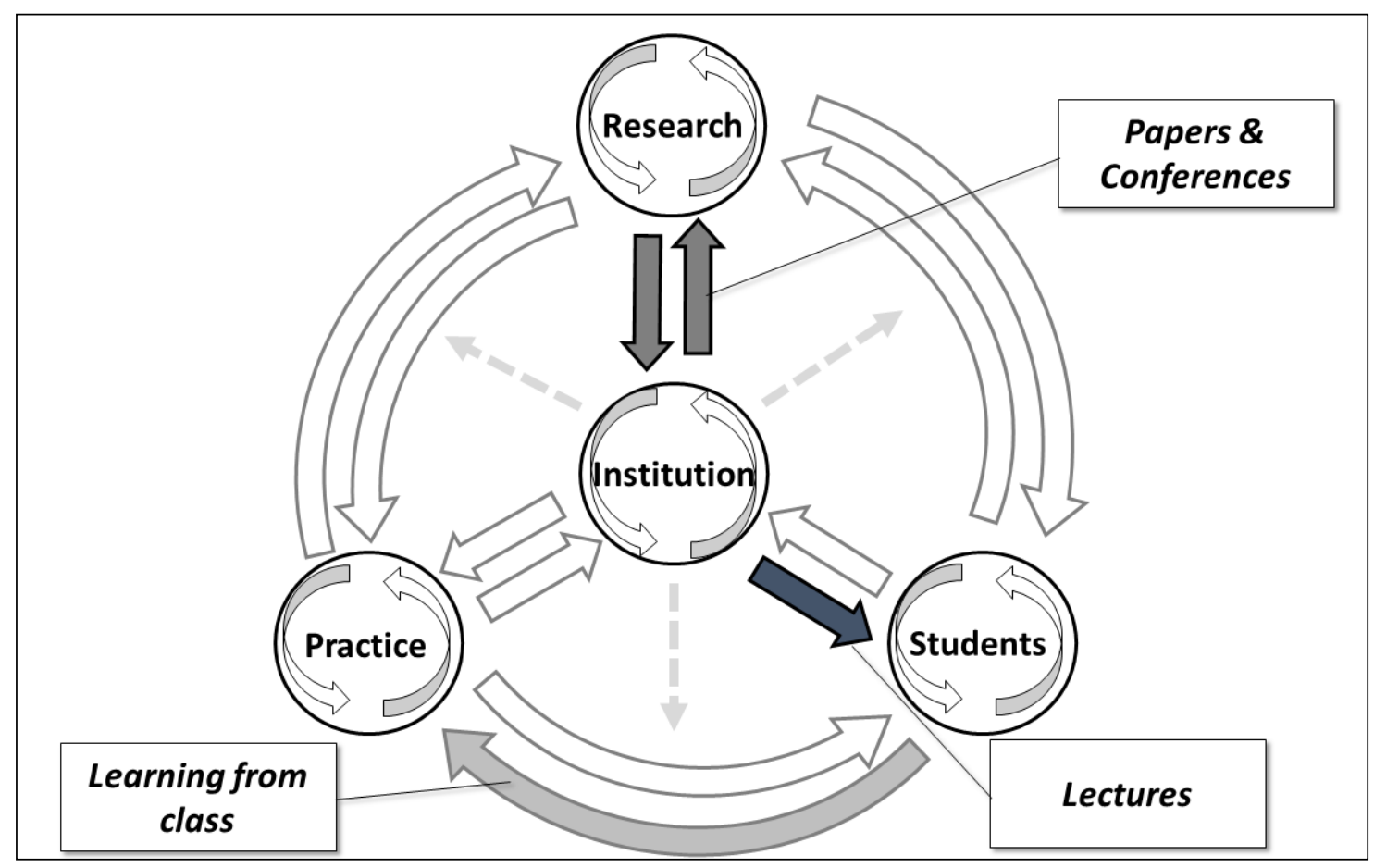

Figure 6. Straw man business school

The principle channels of the straw man business are darkened. In this school, the sole channel for communicating to students is the lecture-which is why only one arrow on the pathway is darkened. It also assumes that some of what has been communicated to students serves to inform employers (the grey arc at the bottom). The institution has a robust communication back and forth with the various disciplinary research communities, but is not highly conducive to interdisciplinary research, so the within research flow is not darkened.

While we have described the straw man school as pathological, it might suffice under some circumstances. According to our theory, it could be an adequate model for a world (a) in which students are homogeneous, (b) where all research questions have a right answer, and (c) where the individual business functions can all operate independently of each other. In other words, in a world of very limited complexity.

\section{The "Informing" Business School}

At the other extreme, we present the "informing" business school, illustrated in Figure 7. Like its straw man counterpart, it is unlikely to exist in its purest form. But in this model, every listed informing path is either directly supported or enabled by the institution, and all are interactive. According to our theory, such an institution would be well suited for a highly complex environment. 
By the same token, it could be unnecessarily complicated and elaborate for the less complex world in which the straw man model would suffice.

Having presented the two extremes of a continuum, we now turn to a case study of USF's Muma College of Business. Our goal is to describe its efforts to move towards the informing business school ideal in addressing with the growing complexity of the business environment.

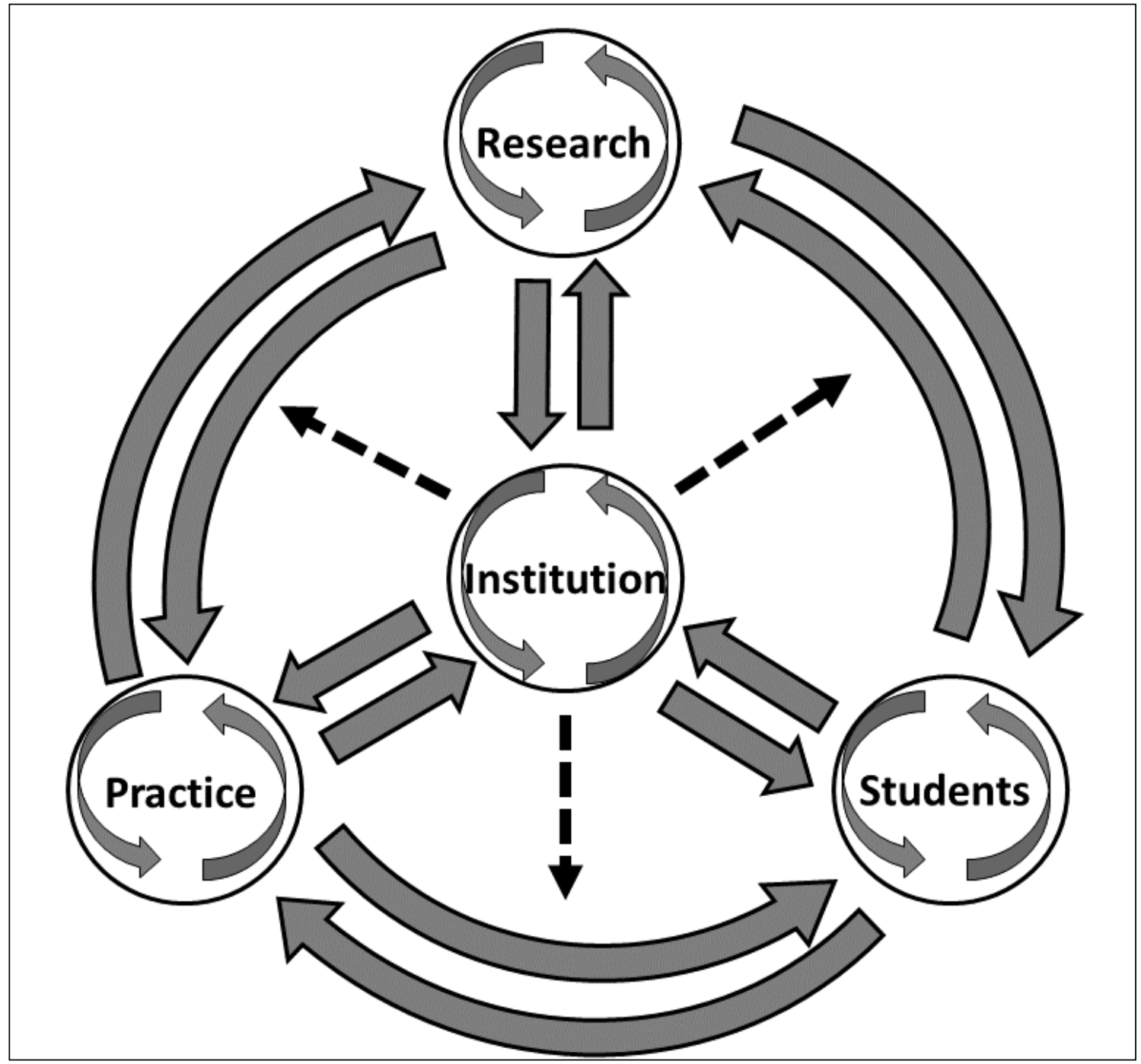

Figure 7. The informing business school: All direct informing pathways and enabled pathways are supported.

\section{Informing at the Muma College of Business}

In this section, we consider various initiatives being conducted and planned by the Muma College of Business (MCOB), organized according to the informing flows framework (Figure 5). We begin, however, with a brief section presenting the background of the college and the methodology employed in the study. 


\section{Background and Methodology}

The investigation described in this paper was conducted using a case study methodology drawing mainly upon internal sources at the MCOB.

\section{Background}

The Muma College of Business is part of the University of South Florida, a research extensive large metropolitan state university located in Tampa, Florida, USA. According to its 2014-2015 Annual Report, as of fall 2014, it had over 5500 students enrolled, roughly $17 \%$ at the graduate level and $83 \%$ undergraduate. At that time, it had 103 faculty members, $83 \%$ of whom were tenured or tenure earning, assigned to four different departments/schools: Marketing, Finance, the Lynn Pippenger School of Accountancy, and Information Systems \& Decision Sciences.

The MCOB's stated mission was as follows:

We emphasize creativity and analytics to promote student success, produce scholarship with impact, and engage with all stakeholders in a diverse global environment.

In 2012, Dr. Moez Limayem joined the MCOB (then known as the USF College of Business) as its new Dean. Upon assuming the role, a number of new programs and policies were initiated, and a number of existing activities that had previously been initiated at the departmental level were given new emphasis.

The study described in this paper was conducted as an attempt to catalog many of these activities. More importantly, it represented an attempt to characterize the informing flows engendered by these activities, to validate the informing flows framework (Figure 5) as a tool for articulating and diagnosing informing systems with multiple stakeholders, and to identify gaps in the informing flows that could be addressed by increasing interaction in existing activities or by adding activities that "excite" low informing flow channels.

\section{Research method}

The study was conducted using an exploratory case research methodology (Gill, 2011). It began with the development of the informing flows framework. This was followed with an initial identification of activities being conducted by the MCOB, drawn from multiple sources. Data collection included the use of unstructured interviews, gathering of archival data, and, in one case, administering a survey. The goal of this process was to identify potential areas of informing impact and to assess the degree to which they could be adequately captured using the framework.

Because the research goals were largely exploratory, efforts to ensure reliability and validity of the data consisted mainly of two separate stages:

1. Members of the research team met and discussed their findings, coming to a consensus regarding how observed informing activities and outcomes should be characterized.

2. Detailed write-ups of activities - included as the appendices of this paper-were sent to the individuals interviewed for confirmation and suggested revisions were incorporated into the final document.

Over the course of these discussions, a number of decisions needed to be made involving classifications. The most significant of these choices are as follows:

- Distinguishing direct institutional informing flows (1-3 in Figure 5) from enabled flows (4-10 in Figure 5). Because these flows often involved the same stakeholders or stakeholders with multiple roles (e.g., a faculty member could be considered an employee of the institution or as a member of the research community), there was often ambiguity regarding the classification of the flow. As a basis for differentiation, those informing ac- 
tivities that were directly controlled by the institution - such as offering a class - and where resources were provided directly by the institution to support the activity were classified as institutional. Those activities where the institution provided a venue for stakeholders without exerting direct control — such as arranging an event involving students and practice or providing course credit for an internship-were classified as enabled by the institution. Where ambiguity remained, the activity was classified as supporting both direct and enabled informing flows.

- Determining if an activity constitutes "research". Different disciplines have very different notions regarding the nature of research. Thus, a question frequently arose regarding whether a particular activity - such as writing discussion cases or applied research done on behalf of an organization - should be classified as research. Because whether or not an activity is described as research can have a substantial impact on the investigator's career prospects, this is an issue of great sensitivity. The approach taken was to take a fairly narrow view of the research $\rightarrow$ research flows (e.g., Is the activity likely to end up in a research journal or will it become the basis of a presentation at a research conference?) and in those cases where outcome seemed unlikely, to classify the activity as having "limited" research flows.

- Classifying startup and expanding activities. A number of the activities being examined were either early in their startup phase (e.g., faculty externships, Muma journals) or were in the midst of a significant expansion (e.g., DBA program, practice centers). In these cases, some of the informing flows that were planned had yet to be observed. These were classified according to intended, rather than observed, informing. This was noted in the appendices and also in the summary table at the end of the section.

- Descriptions of outcomes. There proved to be no one definition of outcomes for many of the activities. Consequently, outcomes were described in both quantitative and qualitative forms and were represented as well as possible in the appendixes. An important opportunity for the informing business school generally and MCOB specifically may be the standardization of reporting and a focus on measurement of outcomes making sure to consider the dual nature of informing interactions.

\section{MCOB Initiatives}

This section considers initiatives of the $\mathrm{MCOB}$, ongoing and planned. Because the objective of the study was to focus on the informing flows that might be less typical of a business school, we do not cover those activities likely to be present at virtually any institution (e.g., the "straw man" flows earlier illustrated in Figure 6). Instead, the emphasis was on initiatives and programs that encouraged informing across stakeholder groups. The section is organized according to areas of overlap between stakeholders, with classification based upon the enabling flows (labeled 4-10 in the Figure 5 informing flows framework). In addition, only a brief summary of each activity is provided in the body of the paper. A more detailed description and an analysis of the classification according to the informing flows framework are provided in the appendices.

\section{Student x Research activities}

Students $x$ Research (SxR, Figure 8) activities are those that are specifically focused on involving students directly in the research process. Because activities involving applied research that relates directly to practice is covered elsewhere (e.g., Student $\mathrm{x}$ Research $\mathrm{x}$ Practice), we focus mainly on academic research in this section.

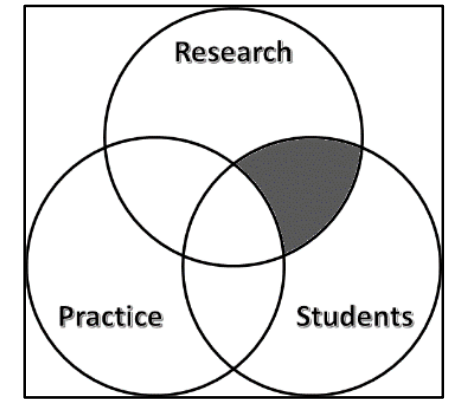

Figure 8: SxR 
Informing Business School

A number of MCOB activities fell within this category. These range from programs widely observed elsewhere to activities that may be less common.

In the "widely observed" category, the MCOB offered a PhD degree in Business Administration (Appendix L). Four different concentrations were available for this degree: Finance, Marketing, Accounting, and Information Systems. The programs had a fairly traditional design, consisting of 90 required graduate credits (30 or more of which usually came from a prior master's degree) and taking four or more years to complete. Being focused on developing academic research skills, the program's emphasis was on developing the prerequisite skills for publication in peer reviewed journals, particularly those that were highly rated.

Slightly less common is the MCOB's undergraduate Business Honors College program (Appendix D), which included a research component, typically leading to an undergraduate thesis. This activity overlapped with the MCOB Symposium of Business Student Research (Appendix R), which was a mini-conference hosted by the institution in which students presented their research findings in poster form.

\section{Student $x$ Practice activities}

Students x Practice (SxP, Figure 9) activities are those where students were placed in situations involving two-way interaction with practice. Many institutions incorporate such activities into their programs. Internships are a particularly common example. The MCOB supported these activities (e.g., Appendix P), but also introduced a number of activities that were both more comprehensive and more unusual.

As was the case for SxR activities, we excluded those activities where research played a central role as well, covering them in the SxPxR category. We note, however, that even the SxP category often included some research-related output.

Student internships (Appendix P) in practice have always been seen as a desirable opportunity for students seeking employment. This

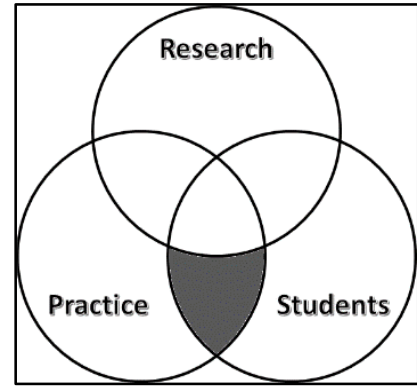

Figure 9: SxP was true and MCOB and elsewhere. After the new dean's arrival in 2012, however, student internships were given a substantially more visible role in MCOB programs, and a program of providing course credit for approved internships was instituted college-wide.

A particularly comprehensive approach to SxP informing can be found in the MCOB's Sports and Entertainment Management (SEM) program (Appendix N). This two year master's program placed a high priority on internships with major sports, entertainment, and marketing organizations, requiring them in its second year. Although the program had only been in operation for two years, the demand for its students was so strong that many first year internships were initiated at the request of participating organizations.

Another example of an activity where students and practice worked together was in the establishment of a student branch of the USF Federal Credit Union (Appendix O). This activity was in its startup phase and involved placing students in a 3 year training program during which they moved from internship roles to actually managing the branch.

Within the finance area, a student run investment fund was established (Appendix Q) that allowed students to acquire a portfolio of stocks under the guidance of over 60 investment professionals from 40 local firms. At the time of the case, the fund had over $\$ 400,000$ under management.

Perhaps the most visible example of SxP activities could be found in the MCOB's entrepreneurship program (Appendix H). Engagement with practice was a central feature of both its degree and non-degree programs. Entrepreneurs routinely joined the classes offered by the program as 
guests. In addition, a variety of venues - including business plan competitions, a Student Innovation Incubator, and a mentorship program - were established by the center.

MCOB also established a number of social programs for students that were built around activities involving practicing executives and managers. The Bulls Business Community (BBC, Appendix C) was a living and learning community that was part of a broader Bulls Business Network that frequently brought managers in to speak to students and interact with them.

The 25 under 25 program (Appendix S) involved identifying 25 young students, highlighting their achievements and sponsoring activities with the local business community, such as an "Elevator Speech" competition where students had to pitch themselves to local executives during a single elevator ride up and down a local high rise. Individual departments also developed activities intended to bring students together with practice. For example, the IS\&DS department sponsored an interview activity where students conducted mock interviews with local hiring managers.

\section{Practice $x$ Research activities}

Practice $x$ Research (PxR, Figure 10) activities are those that involve direct involvement of both academics and practitioners in a research activity. While only two of these activities could be specifically identified in our research (not including those listed in the SxPxR category, which themselves had a significant PxR component), they both played, or were expected to play, an important role in the future of the MCOB.

The first PxR activity was the result of a strategic decision by the MCOB to develop a focus on business analytics and creativity, resulting in the creation of the Center for Analytics and Creativity (Appendix B). Although the center was only recently formalized, it

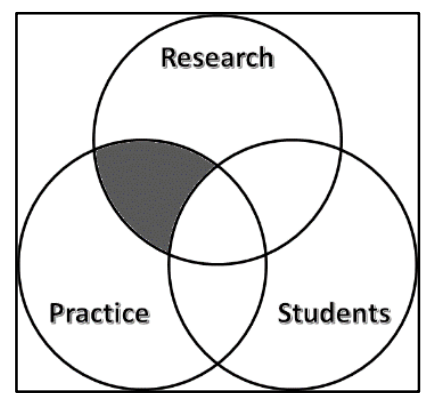

Figure 10. PxR had already hosted an IdeAlytics Fest event bringing together both researchers and executives.

Faculty externships (Appendix I), an innovative program scheduled to launch in spring 2016, was a near-perfect exemplar of PxR informing. This program took the concept of a student internship and generalized it to researchers. Under the program, faculty researchers would be relieved of classroom duties for a semester during which they would be employed by a local business.

\section{Student x Practice x Research activities}

Students x Practice x Research (SxPxR, Figure 11) activities supported the most comprehensive informing channels. In these activities, it was essentially impossible to decompose the informing into two-stakeholder channels. To the contrary, the three stakeholders all participated in such an integrated manner that the activity would largely be rendered meaningless if one of the stakeholders was removed.

One of the most significant initiatives of the MCOB during the previous three years was the launch of its Doctor of Business Administration (DBA) program (Appendix G). The participants in this 3

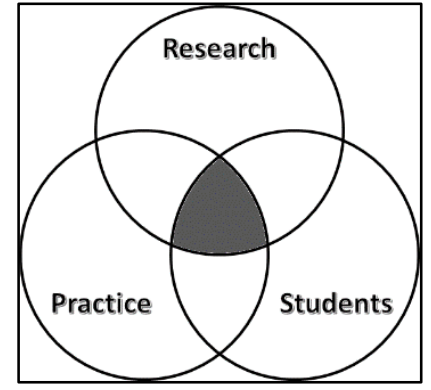

Figure 11: SxPxR year program were all working executives or senior managers with at least 12 years of experience. The initiation of the program, which launched at the beginning of 2015, was largely driven by the broad informing patterns potentially enabled by such programs (Gill, 2015b; Gill \& Hoppe, 2009). 
Another important example of the SxPxR flow comes from the MCOB's case study initiatives (Appendix E). These initiatives included a series a case competitions and a case development initiative - including student development of cases - that had formed the basis for a number of capstone courses in both undergraduate and graduate programs. The classification of this activity as SxPxR rather than SxP was dependent on the degree to which the discussion cases that were developed as part of the initiative were classified as research (as noted in the methodology). Because the initiative had produced two National Science Foundation grants (totaling \$470,000), one Department of Defense grant $(\$ 58,000)$ and a Fulbright research grant to South Africa, the research classification seemed appropriate.

One particularly broad initiative falling into the SxPxR category was the MCOB's involvement in the Florida Center for Cybersecurity (Appendix J). An initiative directly involving four USF colleges, as well as all the other universities in the Florida state system, the institute ran academic programs (MS in Cybersecurity), coordinated student internships and practicums, organized practitioner-researcher conferences, and funded research projects.

An SxPxR activity that was being launched as the current paper was being investigated was the Muma journals (Appendix K), the Muma Business Review (MBR) and the Muma Case Review (MCR). These two journals both evolved out of the DBA program, but had missions to inform students, practice, and research in quite different ways. The MBR was created to provide an outlet for research articles written in a manner that would be accessible to practice; its initial source of articles was the publication courses of the DBA program, with the intention of encouraging submissions from other DBA programs and, eventually, from the broader research community. The MBR, in contrast, was intended to serve as an outlet for discussion case studies and technical notes, and would target a faculty audience.

\section{Other activities}

Only one of the activities examined could not be readily classified according to informing flows that were enabled, rather than being directed, by the institution. The advisory boards (Appendix A) convened by the individual departments and for the MCOB as a whole, represented a direct link between practice and institutional participants (item 3 on Figure 5). On the other hand, these boards did not necessarily involve direct interactions between members and students, or members and faculty members (in their capacity as researchers). Instead, the specific mission of these boards was focused on providing the institution with guidance on curricular issues and, to a lesser extent, on the MCOB's research agenda. The impact of this guidance was often quite substantial. In addition, board members often provided significant financial support to the departments and the college.

\section{Participant Observations}

Consistent with most in situ action research where participants are introduced to the theoretical framework and discuss its application it was interesting to observe participants' reflections on the concept of the informing business school and their particular activity's effect on the informing flows. Routinely the research study participants reacted positively to the framework and were quickly able to place their activity on the spectrum of informing flows.

In each case, participants were frequently able to describe that a flow existed. An interesting observation by the researchers often occurred when participants were asked about the flows in both directions. Frequently, the participant had a paradigm associated with a set of informing flows that went in one direction. For example, the assumption might be that a faculty program created flows that informed students but did not encourage students informing faculty. Or, a paradigm might be that business informed the institution of the type of students needed but the institution 
did not activate a flow informing practice within the same activity. A key observation from the research conducted is that once that paradigm was questioned by the researcher, participants often had an "aha" moment where they then described a list of informing flows that were occurring in the opposite direction.

Likewise, at times the participants would suddenly begin to describe how, with very little additional effort, they might create or enable additional flows with the same activity. For example, the student research symposium leader quickly identified the opportunity to invite practitioners (advisory board members at the very least) to future symposium to "activate" the student to practice informing flow. The researchers were pleasantly surprised by the frequency of this sort of extension of flows just due to the exposure to the framework and an open discussion of existing and aspirational flows.

Finally, the researchers came to a consensus that just having an activity that animated each of the informing flows was not the goal of and not enough to insure a robust informing college of business. As we discuss later, the real goal is to create rich, two-way informing flows in any targeted interaction and to have multiple activities that give depth and breadth to informing in each of the ten informing flows.

\section{Summary}

The planned and ongoing activities of the $\mathrm{MCOB}$, with flows characterized according to the informing flows framework (Figure 5) diagram, are summarized in Table 1. The rightmost column signifies the level of maturity of the activity at the time of the investigation.

\section{Discussion: Resources for Informing}

For any institution whose principal activity is informing, the question of where to acquire the resources necessary to support that informing is critical. As higher education costs continue to rise at a rate that is unsustainable, future sources of those resources become increasingly concerning. For the "informing business school" illustrated in Figure 7, the resource challenge may be particularly acute. Whereas many of an institution's direct informing activities may be modeled as a straightforward transaction (e.g., the student takes a course and pays a tuition fee), the Figure 7 school is heavily involved in enabling activities (items 4-10). For such activities, the acquisition of necessary resources may prove to be considerably more circuitous. Establishing a justification for the return on investment of enabling informing may be difficult, as the benefits of such informing will largely be realized by stakeholders outside institutional boundaries (e.g., by students, by employers, by the community at large). There would seem to exist a continuum of possibilities for resource acquisition for enabling activities, bounded by two extremes:

- Indirect benefits of these enabling activities do not generate increased revenues, meaning their costs must be covered from general funds, such as tuition and state aid.

- The indirect benefits of these enabling activities generate revenues from a variety of sources - e.g., donations, fees and grants - that would not have materialized otherwise.

In the former event, enabling activity funding will demand competition with other, more direct, informing activities. In the latter event, enabling activities can become self-sustaining.

\section{The Resource Challenge}

In considering this issue, we observed that the Table 1 summary of MCOB's portfolio of activities similarly includes a large number of enabled informing flows. As a result, it may serve as a useful exploratory case study with respect to the acquisition of resources for these types of enabled informing flows. In doing so, we looked at outcome results summarized in many of the ap- 
pendices, and also introduced some additional information about resources gathered during the investigation.

Table 1: Mapping of Different Programs to the informing flows framework (Figure 5) categories

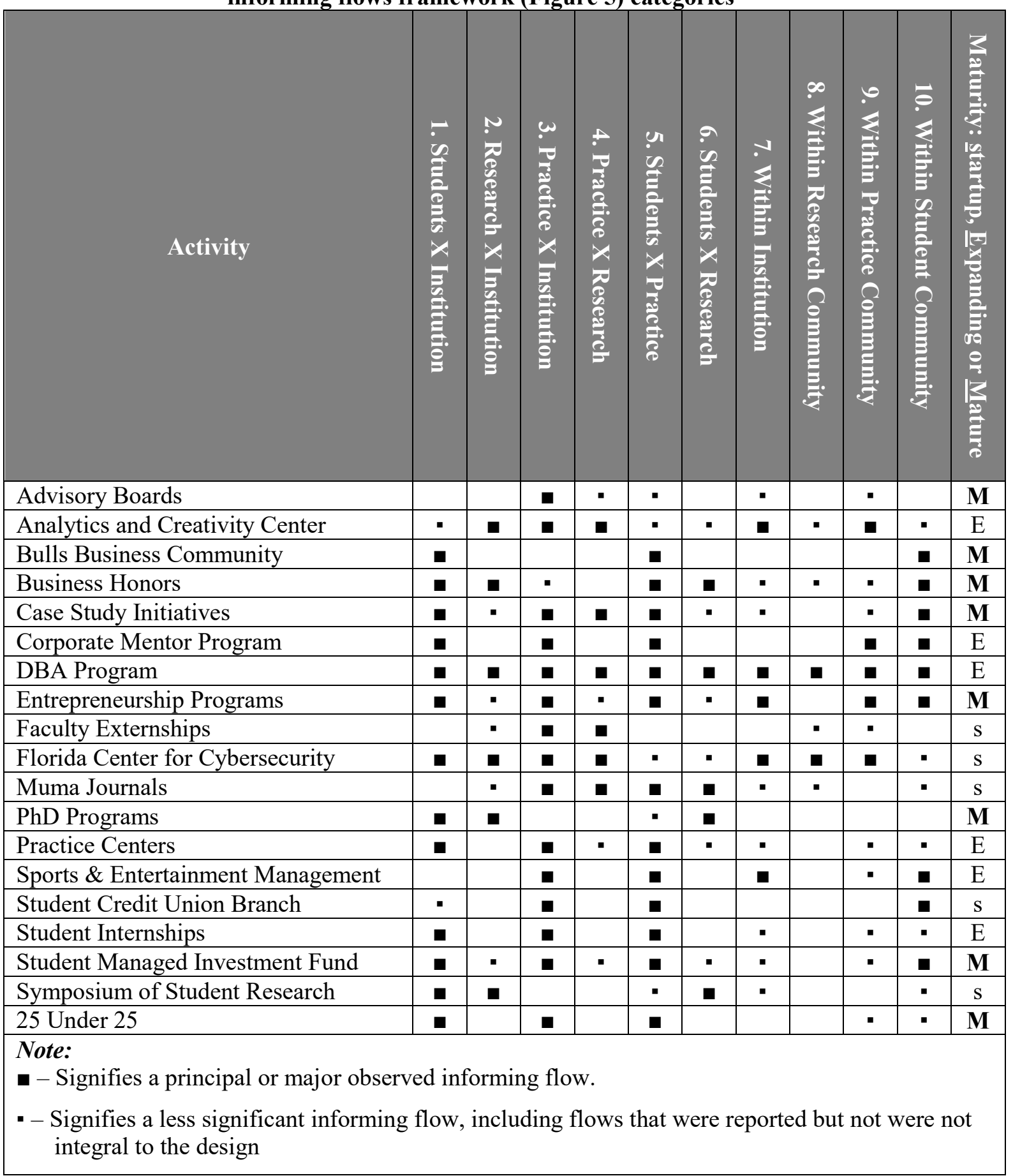

To begin, it is useful to look at where higher education currently gets its resources. Because this differs dramatically across national boundaries and by type of institution, we limit our focus to U.S. non-profit institutions offering at least 4-year degrees, with an emphasis on public institu- 
tions. The U.S National Center for Educational Statistics (NCES) groups revenue into four broad categories (NCES, 2015a):

1. Tuition. $22 \%$ of public revenue, $32 \%$ of private revenue in 2012 .

2. Investments. $4 \%$ of public revenue, $19 \%$ of private revenue in 2012 .

3. Government grants, contracts and appropriations. $38 \%$ of public revenue, $13 \%$ of private revenue in 2012. For public institutions, the breakdown of this revenue was $15 \%$ from grants and contracts, the remaining $23 \%$ from appropriations. For private institutions, virtually all the revenue was from government grants and contracts.

4. Other. $36 \%$ of public revenue, $36 \%$ of private revenue in 2012 . For public institutions, most of the $36 \%$ "other revenue" came from operations (28\%) of auxiliary businesses, such as food services, sporting events, dormitory rentals, bookstores and hospital operations, and most of the remainder (7\%) came from donations. For private institutions, $25 \%$ came from operations, $11 \%$ from donations.

Excluding entry into auxiliary businesses, a public institution that seeks to increase revenue to fund additional informing activities is limited to three main sources over which it has (some) control: increasing tuition revenues, increasing grants, and increasing donations.

Tuition has traditionally been the easiest revenue source for public institutions to tap, with tuition increases being accepted as a fact of life. For example:

Between 2007-08 and 2012-13, revenues from tuition and fees per full-time-equivalent (FTE) student increased by 17 percent at public institutions (from $\$ 5,478$ to $\$ 6,415$, in constant 2013-14 dollars) and by 7 percent at private nonprofit institutions (from $\$ 18,550$ to $\$ 19,866)$ (NCES, 2015a).

For research institutions following a focused informing model approximating that of the Figure 6 "straw man", a plausible path driven by research informing might therefore be the following:

- Invest more resources in research, leading to:

- Increased reputation for the school

- Increased reputation leads to:

- Increased demand for enrollment, both from U.S. and international sources

- Increased success rates for grant proposals

- Increased demand for enrollment leads to tuition increases from:

- Price hikes, both from tuition raises and increased international students (at institutions charging differently for local an non-resident students)

- Increased enrollment

- Increased grant success rate leads to increased grant revenue

This strategy becomes problematic, however, in environments where government support is declining, tuition increases are being resisted, and demographic trends are slowing the rate of enrollment growth. For example, between 2006-2007 and 2012-1013, government support dropped from $42 \%$ to $38 \%$ of total revenue for public institutions (NCES, 2015a; Table 333.10). In addition, many U.S. states, including Florida, started to resist, or even prohibit, tuition raises within their respective state university systems. Finally, enrollments in U.S. undergraduate programs stabilized in 2010, falling for several years and not returning to their 2010 levels until 2015 (NCES, 2015b)

Public business schools seeking to employ the above research-focused strategy for acquiring additional resources described above also face some significant disadvantages. Specifically: 
- Donations: Institutions receiving public funding have typically been at a disadvantage in seeking donations, as evidenced by the substantial disparity in percentage of revenue received from investments as well as the lower percentage directly from donations.

- Grants: For business schools, research grants have traditionally played a much smaller role in generating revenue than they do for their medical and engineering school counterparts.

- Visibility: Business academic research is often criticized for its low visibility to practice (e.g., Gill, 2010). Thus, its ability to generate revenues from practitioner stakeholder sources through research reputation tends to be limited.

- Competition: As many institutions focused on enhancing their research reputation, spurred by accrediting agencies that placed a growing weight on research performance, the amount of resources needed to produce material gains in research ranking grew correspondingly.

Collectively, these factors make the quest for resources through a pure research strategy increasingly problematic.

\section{Direct Resources from MCOB Informing Activities}

The experience of the MCOB initiatives is very different from the narrowly focused straw man example. Of the activities listed, very few involve a substantial net expense. The major exception to this rule was the $\mathrm{PhD}$ program, which generated negligible revenue (since tuition was mainly waived) accompanied by substantial costs for student stipends, instruction and advising. A direct contrast to this was the DBA program, which had the potential to generate substantial net contribution, offering neither tuition waivers nor stipends. Many of the other activities generated small amounts of net contribution, with the remaining activities generating losses that were usually modest. The approximate resource implications of the various activities, presented in terms of orders of magnitude, are summarized in Table 2 . While developing an exact tally was outside the scope of the investigation, complicated by the dynamic nature of each activity, the overall combined effect seemed most likely to be a slight net cost to the MCOB, although it could swing either way in a given year.

Part of the reason that the net costs of these programs were so limited is that they often came with associated sources of revenue, many of which are referred to in the appendices. These sources included:

- Revenue from fees, such as tuition, that were associated with most of the activities that involved course work

- Revenue from contracts and grants, such as the NSF grants that helped to fund the case initiatives and the payments from organizations used to fund practice centers

- Donations in cash, such as those frequently made by advisory board members

- Donations in kind, such as the time spent on activities by volunteers

The last of these was particularly significant, since volunteer time often represented an integral element of the informing flows that have been described. Ultimately, successful identification, receipt, and distribution of funds to pay for these non-traditional informing activities required an active effort on the part of the Dean, administrators, and department chairs acting in concert (and sometimes creatively within the strictures of university systems, regulations, and guidelines). 
Table 2: Resource Implications of Informing Activities (Estimated for 2016)

\begin{tabular}{|c|c|c|c|c|c|c|c|}
\hline Activity & 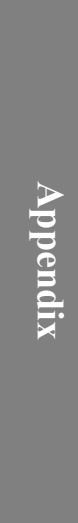 & 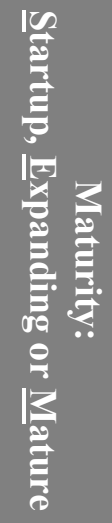 & 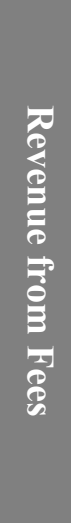 & 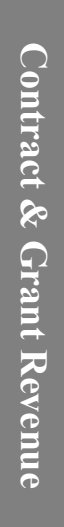 & 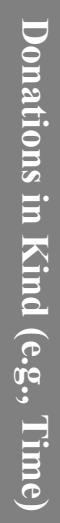 & 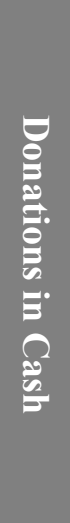 & 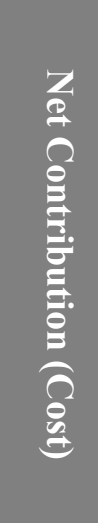 \\
\hline Advisory Boards & $\mathrm{A}$ & $\mathrm{M}$ & & & + & + & $\$$ \\
\hline Analytics and Creativity Center & $\mathrm{B}$ & $E$ & & + & + & & $(\$)^{*}$ \\
\hline Bulls Business Community & $\mathrm{C}$ & $\mathrm{M}$ & + & & + & & $(\$)$ \\
\hline Business Honors & $\mathrm{D}$ & $\mathrm{M}$ & & & + & & $(\$)$ \\
\hline Case Study Initiatives & $\mathrm{E}$ & $\mathrm{M}$ & & + & + & & $=$ \\
\hline Corporate Mentor Program & $\mathrm{F}$ & $E$ & & & + & + & $=$ \\
\hline DBA Program & $\mathrm{G}$ & $\mathrm{E}$ & + & & & & $\$ \$ \$$ \\
\hline Entrepreneurship Programs & $\mathrm{H}$ & M & + & + & + & & $\$$ \\
\hline Faculty Externships & $\mathrm{I}$ & $\mathrm{S}$ & & + & + & + & $=$ \\
\hline Florida Center for Cybersecurity & $\mathrm{J}$ & $\mathrm{S}$ & + & + & + & & $\$ \$$ \\
\hline Muma Journals & $\mathrm{K}$ & $\mathrm{S}$ & & & + & & $(\$ \$)$ \\
\hline PhD Programs & $\mathrm{L}$ & $\mathrm{M}$ & + & + & & & $(\$ \$ \$)$ \\
\hline Practice Centers & $\mathrm{M}$ & $\mathrm{E}$ & & + & & + & $\$ \$$ \\
\hline Sports \& Entertainment Management & $\mathrm{N}$ & $\mathrm{E}$ & + & + & + & + & $=$ \\
\hline Student Credit Union Branch & $\mathrm{O}$ & $\mathrm{S}$ & + & & + & & $=$ \\
\hline Student Internships & $\mathrm{P}$ & $\mathrm{E}$ & + & & + & & $(\$)$ \\
\hline Student Managed Investment Fund & Q & $\mathrm{M}$ & + & & + & + & $\$$ \\
\hline Symposium of Student Research & $\mathrm{R}$ & $\mathrm{S}$ & & & & & $(\$)$ \\
\hline 25 Under 25 & $\mathrm{~S}$ & $\mathrm{M}$ & & & + & + & $=$ \\
\hline
\end{tabular}

\section{Broader Sources of MCOB Resources}

Looking at the revenue implications of the various MCOB informing activities individually captured only part of the total resource picture. Collectively, the informing flows exerted a combined effect:

- Dramatically increasing the visibility of the MCOB within the local community, largely because all of the activities summarized in Table 1 involved practice, and the vast majority involved students.

- Building a perception that the MCOB had become an engine of local business change, largely because so many new activities were being introduced and existing activities expanded (see rightmost column of Table 1). 
This collective effect appeared to be an important contributor to a series of donations that could not be tied to any one particular activity. These included the following:

- In October 2014, the college received a \$25 million donation from Pam and Les Muma, two alumni of the university, and was renamed the Muma College of Business.

- In February 2015, Lynn Pippenger, an alumna of the college, donated $\$ 10$ million to the School of Accountancy, which was renamed the Lynn Pippenger School of Accountancy in her honor.

- In August 2015, Barron (Barry) Collier III and his wife, Dana, donated \$10.85 million to the MCOB to establish the Collier Center for Student Success, supporting events, workshop and mentoring activities intended to improve graduation rates and job placement.

- In February 2016, a \$2.9 million dollar give to the Center for Entrepreneurship launched the Frank and Ellen Daveler Entrepreneurship Program at USF's Muma College of Business, with a focus on funding student scholarships and entrepreneurship competitions.

In addition, a number of smaller grants - totaling several million dollars - were received during the same period. The MCOB further received a substantial allocation from a grant to form the Zimmerman School of Advertising as a consequence of the joint participation of the MCOB Marketing department in advertising majors offered by USF's College of Arts and Science.

As stated previously, it is impossible to tie these donations to specific informing activities of the MCOB. Nevertheless, it is equally inconceivable that the highly visible activities and stream of new initiatives coming out of the MCOB had no impact on the donors' respective decisions to donate. Thus, the tentative conclusion of this analysis is that supporting the broad informing paths listed in the informing flows framework may stimulate giving from the various stakeholders being informed. Referring back to the earlier resource continuum of possible sources, the MCOB's experience is strongly skewed towards the second outcome, namely:

The indirect benefits of these enabling activities generate revenues from a variety of sources - e.g., donations, fees and grants - that would not have materialized otherwise.

\section{Limitations and Directions for Future Research}

As exploratory case study research, much of the investigation's value was expected to be from clarifying the nature of the phenomena observed and identifying what issues that warrant further research. We now consider some of the limitations of the research and directions for future research.

\section{Limitations}

Overall, the informing flows framework employed in the research proved to be a powerful tool for identifying and characterizing informing flows at the MCOB. In applying the tool, however, we noted a number of limitations:

1. While identifying informing flows generally proved to be straightforward, quantifying their magnitude and impact was not. A Table 1 "big square" for one activity might well be far more or less significant than an identical "big square" for another activity. Particularly if the tool was to be used to develop a composite picture of informing flows, an instrument for gauging the magnitude of informing flows would need to be devised.

2. The fact that an informing flow exists does not necessarily imply that it has a significant impact on behavior. While we attempted to make a preliminary assessment of outcomes for the various activities, it is not necessarily the case that these outcomes could solely be attributed to informing flows. 
3. Because the investigation specifically focused on identifying informing flows enabled by the $\mathrm{MCOB}$, activities dominated by direct informing flows - such as requirements for faculty research and the delivery of undergraduate/graduate degree programs - were not considered. We take it as self-evident that these more traditional programs represent the bulk of informing activities at most business schools, including MCOB. A full picture of an informing business school, particularly one where flows are quantified (see item 1), would necessarily require that these be incorporated into the model.

4. While we believe that the informing activities documented in the investigation had a material impact upon the unusually large influx of resources (i.e., donations) over the 2014-2015 period, evidence of causality is scant. This is clearly a worthy topic for future research.

5. Although we found ample evidence for the various informing paths described in the informing flows framework, we did not acquire evidence either to support or deny their relationship to underlying environmental complexity and client diversity. Thus, while the theoretical complexity-informing relationship was proposed as a basis for the model, it remains to be tested. It is not clear that case study research methodologies will be effective for this type of research question.

With respect to the research approach itself, any single case methodology, especially an exploratory case study, is bound to raise questions of generalizability. We tried to address this by creating contrasting "straw man" (Figure 6) and "informing business school" (Figure 7) models that would allow researchers at other business schools to formulate a classification of their own school's activities and outcomes, thereby determining where they fit on the continuum between the two extremes. Effectively, this leaves the second case in the two case comparison to be left to the reader. While this might be less satisfying from a methodological perspective, even if we had wanted to identify a second business school that was closer to the "straw man" informing pattern, we do not see how such would be possible without a completely valid concern that the example was cherry picked.

\section{Directions for Future Research}

Not surprisingly, the directions for future research raised by this study parallel a number of the observed limitations. In addition, some have been informed by our experience in conducting the research. Among the areas for future research that we envision are the following:

1. Use in Identifying Opportunities: Although the informing flows framework was developed as a tool for data gathering, as we applied it we frequently found ourselves speculating about possible informing opportunities it suggested. Specifically, the process of identifying the informing flows supported by an activity necessarily involved identifying unsupported paths. What we observed was that immediately after identifying these gaps, we began asking questions about how the activity might be modified in order to fill them. An interesting research study could be built around studying the impact of framework-inspired expansions to informing flows.

2. Studying Informing Flows vs. Resource Availability Causal Relationships: As already noted, the current research was unable to confirm direct causality between informing flows and resource acquisition. This relationship obviously warrants further investigation. One stream of research within this broad area might involve the dynamism of informing patterns. Anecdotally, some of the MCOB's major donors commented that they were inspired by the perceived "trajectory" of the school. Drawing a parallel to physics, a school's trajectory might be determined by its position (mature activities), its velocity (expanding activities) and its acceleration (startup activities). Further research might suggest which of these, or what balance between them, might prove most effective in creating a trajectory that attracts donations. 
Informing Business School

3. Building a Suitable Informing Portfolio: The MIS field has long advocated creating a portfolio of projects and applications that are an appropriate fit with the competitive environment (e.g., Cash, McFarlan, \& McKenney, 1988). Research on how this concept might be extended to informing flows and maturity of activities could provide prescriptive recommendations for administrators and faculty seeking to better position their institutions from an informing standpoint.

4. Advancing Informing Theory: As noted in the limitations section, further research is needed if the relationship between complexity/diversity and breadth of informing flows is to be supported. Such research would likely need to be part of a long term program, since - at the present time - none of the variables involved are easily quantified or measured.

\section{Conclusions}

The present paper describes an exploratory case study investigation into the informing flows that can be enabled by a business school. Its principal source of evidence is a case study of the Muma College of Business at the University of South Florida. The key conclusions of the investigation are as follows:

- Academic institutions are often perceived in terms of the direct informing flows that they support, such as degree programs offered and research published by faculty. What the study proposes is that an important aspect of the institution's informing may stem from activities that enable — but do not provide specific control over - informing between stakeholders.

- Building on informing science theory and current trends in U.S higher education, we argue that enabled informing may need to become an increasingly large part of a business school's mission if it is to succeed in an environment of growing complexity and client diversity.

- Institutions may enable informing flows in a variety of ways. Among those observed in the study are providing venues or outlets for informing activities, organizing stakeholder activities (without necessarily controlling their content), providing institutional recognition (e.g., course credit, recognition for purposes of compensation, promotion and tenure, stipends and other funding) for activities, and publicizing the activities.

- The informing flows framework for specifying both direct and enabled informing flows can be a robust tool for identifying and categorizing the informing implications of individual activities.

- Many activities that involve enabled informing flows can concurrently generate some or all of the resources needed to support themselves. These resources may come through a mix of donations, fees, and in-kind support. In the case studied, the observed costs of expanding enabled informing flows were not prohibitive. In many cases, the net contribution generated by a particular informing activity proved to be demonstrably positive.

The study further noted that in the case of the MCOB, a period of rapid expansion of enabled informing flows that occurred between 2012 and 2015 was accompanied by a major spike in donations from stakeholders, close to $\$ 50$ million in total amount. Although solid evidence of a causal relationship between the pattern of informing flows and donations could not be established, we conclude it to be unlikely that the many new informing activities initiated during that period had no effect on donor perceptions. 


\section{References}

AACSB. (2006). Business and business schools: A partnership for the future. Report of the AACSB International Alliance for Management Education Task Force. Retrieved from http://www.aacsb.edu/ /media/AACSB/Publications/research-reports/business-and-businessschools.ashx

AACSB. (2008). Final report of the AACSB International impact of research task force. AACSB International, Retrieved from http://www.aacsb.edu/resource_centers/research/Final/Impact of_Research_ReportFINAL.PDF

AACSB. (2015). Eligibility procedures and accreditation standards for business accreditation. AACSB International, Retrieved from http://www.aacsb.edu/ /media/AACSB/Docs/Accreditation/Standards/2013-bus-standardsupdate-jan2015.ashx

Cash, J. I., McFarlan, F. W., \& McKenney, J. L. (1988). Corporate information systems management: The issues facing senior executives (2nd ed.). Homewood, IL: Irwin.

Gill, T. G. (2010). Informing business: Research and education on a rugged landscape, Santa Rosa, CA: Informing Science Press.

Gill, T. G. (2011). Informing with the case method, Santa Rosa, CA: Informing Science Press.

Gill, T. G. (2012). Informing on a rugged landscape: Homophily versus expertise. Informing Science: The International Journal of an Emerging Transdiscipline, 15, 49-91. Retrieved from http://www.inform.nu/Articles/Vol15/ISJv15p049-091Gill616.pdf

Gill, T. G. (2014). Launching the DBA program at USF. Informing Faculty, 2(4), 1-30. Retrieved from http://informingfaculty.org/v2n04-USF-DBA.pdf

Gill, T. G. (2015a). Informing science, volume one: Concepts and systems, Santa Rosa, CA: Informing Science Press.

Gill, T. G. (2015b). Informing science, volume two: Design and research issues, Santa Rosa, CA: Informing Science Press.

Gill, T. G., \& Hoppe, U. (2009). The business professional doctorate as an informing channel: A survey and analysis. International Journal of Doctoral Studies, 4, 27-57. Retrieved from http://ijds.org/Volume4/IJDSv4p027-057Gill267.pdf

Gill, T. G., \& Mullarkey, M. (2015). The Interdisciplinary business doctorate for executives: A novel way to bridge academic research and practice. Systemics, Cybernetics and Informatics, 13(6), 116-121. Retrieved from http://www.iiis.org/CDs2015/CD2015IMC/IMCIC_2015/PapersPdf/ZA252RN.pdf

Gill, T. G., \& Ritzhaupt, A. (2013). Systematically evaluating the effectiveness of an information systems capstone course: Implications for practice. Journal of IT Education: Research, 12, 69-94.

Kauffman, S. A. (1993). The origins of order. Oxford, UK: Oxford University Press.

Kuhn, T. S. (1970). The structure of scientific revolution (2nd ed., enlarged). Chicago, IL: University of Chicago Press.

Murphy, W. F., Murphy, S. S., Buettner Jr., R. R., \& Gill, T. G. (2015). Case study of a complex informing system: Joint interagency field experimentation (JIFX). Informing Science: the International Journal of an Emerging Transdiscipline, 18, 63-109. Retrieved from http://www.inform.nu/Articles/Vol18/ISJv18p063-109Murphy1655.pdf

NACE. (2015). Internship \& co-op survey report. National Association of Colleges and Employers. Retrieved from https://www.naceweb.org/uploadedFiles/Content/static-assets/downloads/executivesummary/2015-internship-co-op-survey-executive-summary.pdf 
Informing Business School

NCES. (2015a). Postsecondary revenues by source. National Center for Educational Statistics, updated May. Retrieved from http://nces.ed.gov/programs/coe/indicator_cud.asp

NCES. (2015b). Digest of education statistics, 2013 (NCES 2015-011), Chapter 3, Table 303.70, Retrieved from http://nces.ed.gov/programs/digest/d13/tables/dt13 303.70.asp?referrer=report

Weiss, I (2015). Focus on advisory boards: The big picture view. BizEd, 6, November/December. Retrieved from http://www.bizedmagazine.com/archives/2015/6/features/focus-on-advisory-boards-bigpicture?utm source

Will, R., \& Skaggs, R. (2014). University of South Florida Credit Union and USF College of Business: Marshall Center branch. Informing Faculty, 2(2), 1-12. Retrieved from http://informingfaculty.org/v2n02-USF-FCU.pdf 


\section{Appendix A: Advisory Boards}

A critical success factor for any college of business pursuing AACSB accreditation is the establishment of advisory boards. In the fall of 2014, the AACSB established the Alliance for Management Education (AME) to explore ways to established "broad-based" partnerships that serve the interests of business and business schools. The AME, in turn, asserted "the position that a viable partnership between business education and business leaders can only be achieved by developing mechanisms that facilitate business leader engagement in activities that influence the processes of business schools" (AACSB, 2006, p. 11).

A key mechanism identified by the AACSB as a best practice for establishing business leader engagement that generates solid partnering is the business advisory board at the college and department level. Goals of advisory boards can include:

1. Business school leaders that are "more informed and attuned to what potential employers want their new hires to know";

2. Employers that "realize substantive advantages" by hiring graduates who (do to the relevance of the curriculum) are quicker to add real value to the enterprise earlier;

3. Fostering more interaction between students and business leaders that leads to stronger rapport and mutual understanding of needs and opportunities available to these key business school stakeholders;

4. Sustained, meaningful connectivity of business leaders to current research, knowledge centers, and interaction with intellectual leaders;

5. And, a structure for the regular engagement between the business school leadership and the business community leadership.

Business school advisory boards at the USF Muma College of Business exist at the college and department levels and generally consist of 10-20 industry professionals and 1-2 community leaders. (Advisory board members by department: Accountancy (36), Finance (11), Marketing (12), Information Systems (17), College (34)) Advisory boards typically meet formally once or twice per fall and spring semester for one-half day. Advisory board meetings typically include a review of recent academic, student, and research successes; a review of curriculum changes under development or review; a discussion of recent community or industry initiatives, needs, demands that might affect job opportunities, curriculum needs, or research efforts; and a general networking opportunity involving the faculty, students, and business leaders in attendance (Weiss, 2015).

At the USF Muma College of Business, Advisory Board members are frequently chosen on their ability to:

1. Influence their organization and other businesses to hire interns, accept practice center projects, and hire new graduates;

2. Facilitate faculty access to practice relevant research opportunities;

3. Provide guidance and advice on curriculum development, student internships, job placement, and marketing the department's/college's intellectual contributions;

4. Network with other members of the advisory board to increase collaborative opportunities within and between members of the business community centered on the USF Muma College of Business.

\section{Outcomes}

Department chairs were contacted to identify tangible outcomes from the activities of their respective advisory boards. They reported the following: 


\section{Marketing:}

- Input from advisory board used when the MS in Marketing curriculum was revised;

- The advisory board recommended the addition of a Project Management course to the Marketing curriculum;

- Each advisory board member serves as a mentor or takes a student as an intern annually at their firm.

\section{Accounting:}

The Accounting upper level Advisory Council (consisting of C-suite executives, partners, and directors at accounting firms) has:

- Provided donations for annual study abroad scholarships;

- Funded a professorship;

- Made introductions to student opportunities - especially for study abroad programs;

- Assisted with faculty recruiting (e.g., to woo undecided faculty to whom offers have been made);

- Participated as guest speakers primarily in our Master of Accountancy program but also in the undergraduate program;

- Served doctoral student research by serving as participants for research studies.

The Accounting lower level Advisory Board (consisting mainly of alums 2-3 years postgraduation) has:

- Sponsored a number of student-oriented annual events including a "welcome back" picnic in September, a CPA exam workshop, professional development workshops, a graduation reception, and the biggest event they help with is the May CPE conference (a large fundraiser that netted some \$130k in 2015);

- Participated as guest speakers primarily in our Master of Accountancy program but also in the undergraduate program;

- Served doctoral student research by serving as participants for research studies.

\section{Finance:}

The Finance Advisory Board was formed in the fall of 2015 and met for the first time that semester. Immediately, the Advisory Board was instrumental in the finance curriculum revision undertaken by informing the finance faculty of what was lacking and what was working well.

- Members helped establish a number of relationships that expanded student internships.

\section{Information Systems and Decision Sciences:}

- Provided input on strategic initiatives and directions for the department;

- Provided periodic and ongoing review of courses, programs and syllabi;

- Provided numerous internship and job opportunities for students;

- Provided numerous business engagement opportunities for the department.

\section{Informing Flows}

The informing flows for this activity are 3, 4, 5, 7 and 9 as described below:

1. Institution to student: None

2. Institution to research: None 
3. Institution to practice: The Advisory Board is directly informed in matters of curriculum, student development, research and activities. They provide feedback and guidance on the same.

4. Research to practice (enabled): Limited. Informing practice of research and creating a mechanism that causes active discussion of research activities with practice

5. Practice to students (enabled): Limited. The involvement of many student presentations and discussions centered on their success in scholarship, internships, practice center projects, and mentoring programs informs business leaders. Advisory board business leaders in turn inform students on additional opportunities.

6. Research to students (enabled): None

7. Within institution (enabled): Limited generally to the multi-disciplinary interaction at the college level advisory board where multiple departments exchange information with business leaders in one forum. None between colleges.

8. Within research (enabled): None

9. Within practice (enabled): Limited. Advisory Board members interaction and networking is encouraged and facilitated during and between advisory board meetings.

10. Within students (enabled): None 


\section{Appendix B: Analytics and Creativity Center}

The mission of the Center for Analytics and Creativity at the USF Muma College of Business is "to facilitate the discovery and dissemination of insights through the power of analytical and creative thinking". The Center accomplishes this mission by:

1. Promoting cutting-edge research to address business and organizational challenges with a focus on research on analytics and creativity.

2. Disseminating research to the business community that can be directly actionable for industry partners.

3. Providing relevant mentoring for analysts and executives through retreats, "on-call" advice on analytical and innovative initiatives, and educational curriculum to industry partners.

4. Providing a forum for networking where industry partners can learn the latest advances in analytics and creativity.

In its mission, the Center is designed to be the advocate for the infusion of analytics and creativity into everything the USF Muma College of Business does - from curriculum to research to business connectivity and partnerships. The Center is designed to be a self-sustaining entity that is funded primarily through industry partnerships and that supports analytics and creativity focused business research by the college primarily through grants and research awards to deserving faculty and students.

\section{Background}

The Center was created primarily to insure that the USF Muma College of Business strategic priority - Strategic Priority 1: Distinctive Identity: Business Analytics and Creative Solutions - had a sponsoring set of leaders with responsibility for leadership and sponsorship of the most promising business analytics and creativity focuses initiatives in the college.

The center approached this mission with a focus on engaging scholarship internally and industry partners externally who were interested in advancing innovation in business analytics and creativity. Partnership funding of these research initiatives was designed around paid levels of Partner engagement with Gold level partners investing \$1 million annually and Silver level partners investing $\$ 500,000$ annually in order to receive various levels of full time faculty effort, $\mathrm{PhD}$ student project effort, post-doctoral research efforts, membership on the Center's governance organizations, and briefings on relevant research and trends.

A key annual event sponsored by the Center is the IdeAlytics Fest to emphasize the intersection of creativity and analytics. The IdeAlytics Fest featured a program with two keynote speakers from Big Data companies and innovation think tanks as well as local innovators that cut across the arts and sciences. IdeAlytics Fest gave participants an opportunity to engage and interact with keynote speakers as well as with other analytical innovators from the Tampa Bay area. The agenda included presentations by:

Dean Moez Limayem, Professors Jank and Heath - Introduction

Gerard J. Tellis, Professor of Marketing, University of Southern California - Breaking the Incumbent's Curse: How to Create a Culture of Unrelenting Innovation

Alon Friedman, Professor, School of Information, USF - The Power of Data Visualization with $\mathrm{R}$

Merry Lynn Morris, Instructor, School of Theatre \& Dance, USF - Mobilizing Possibilities: Dance, Disability, and Technology 
Tim Heath - The Wide Lens: Something Borrowed (Applied Analytics)

Chris Volinsky, AVP, Big Data Research, AT\&T - Shaping Cities of the Future Using Mobile Data

Jim Stikeleather, Chief Innovation Officer, Dell - Reflections on the Day: Analytics, Creativity, and Their Intersection

\section{Outcomes}

Center for Analytics and Creativity Outcomes: In its first full year of operation the center achieved the following outcomes:

- Researchers affiliated with the Center published 4 peer-reviewed articles, 4 peerreviewed conference papers, 1 non-reviewed conference paper, and 7 reports that are currently under review at journals.

- Two research stipends were awarded researchers who proposed research consistent with the goals of the Center for the next academic year.

- The first annual USF Muma College of Business IdeAlytics Fest had participation from approximately 100 academics, students, and business practitioners.

- Conducted a competition to identify a logo for the Center that generated 50 entries from 20 participants.

- The Center developed a Facebook page (www.facebook.com/analyticscreativityusf) as a clearing house for news related to analytics and creativity that has been liked by 139 people though some posts have been seen by more than 190 people. The Center intends to add paid advertising and a graduate assistant who will be able to help generate more systematic reports and newsletters related to the center's activities and interests.

\section{Informing Flows}

The principal informing flows appeared to be 2-4, 5, 6, 7, 9 and 10 as described below (major flows in bold):

1. Institution to student: Limited. The principle flow was from presenters at the annual IdeAlytics Fest Conference to the audience members (including students) on innovations in business analytics and creativity.

2. Institution to research: The Center is designed to promote a surge in research conducted at the college that emphasizes business analytics and creativity and informs the broader research and practice community.

3. Institution to practice: The Center is designed to engage the business community in partnering efforts to identify and disseminate innovation in business analytics and creativity.

4. Research to practice (enabled): The Center seeks to be the facilitator of broader informing between the business community and research into business analytics and creativity.

5. Practice to students (enabled): Limited. In the long run, the Center seeks to build partnering opportunities for students and faculty to engage with businesses to analyze and resolve interesting and topical problems in the areas of business analytics and creativity.

6. Research to students (enabled): Limited. The principal area of impact is intended to be on doctoral level research conducted with support from the Center through its industry partnerships. 
Informing Business School

7. Within institution (enabled): The Center seeks to engage multiple disciplines within the college and between colleges to exploit all innovative efforts that can lead to the creation and co-creation of innovation in business analytics and creativity.

8. Within research (enabled): Limited initially, with the hope that it will foster interdisciplinary initiatives and collaborations with other research institutions.

9. Within practice (enabled): The Center seeks to provide a forum for cross-pollination within the business community of innovative efforts and research in business analytics and creativity.

10. Within students (enabled): Limited. The Center seeks to provide a forum for crosspollination within the business college's student population of innovative efforts and research in business analytics and creativity. 


\section{Appendix C: Bulls Business Community}

The Bulls Business Community (BBC) is a living and learning community in which selected undergraduate business residential students are housed together in the same dormitory area. Not only do participants reside together, they are also given access or first priority to an array of special activities. According to the program's website (http://www.usf.edu/business/undergraduate/bbc/), these include:

- Innovative Learning: Programs such as "Improv Night" provide fun, innovative ways to learn business skills.

- Special Programs: BBC students enjoy exclusive programs such as "Business Etiquette", "Dress for Success", "Résumé Building", and off-site company tours.

- Exclusive Access: Residents are treated to networking opportunities unavailable to most students, such as dinner with the dean or lunch with the Dean's Executive Advisory Council.

- Advising Privileges: Residents have academic advising in the hall, led by a designated Muma College of Business advisor.

- Peer Opportunities: Tutoring is available as well as opportunity for group study since everyone is enrolled in similar courses and the RAs are business students.

- Service Opportunity: Residents often serve as ambassadors for the college and participate in community service activities.

Members of the BBC were automatically included in the broader Bulls Business Network (BBN), a program for high-achieving freshmen that included special access to BBN-only courses and more personalized advising.

\section{Background}

When USF was founded in 1956, it was originally an upper division (i.e., Junior and Senior undergraduate) college consisting almost entirely of commuter students. Over time, the institution evolved to a major research university, offering a full range of graduate and professional programs (excluding Law School). Despite this growth, however, the university's undergraduate programs - particularly business - continued to be dominated by commuter students that attended only upper division classes. This was enabled by state-mandated matriculation agreements that provided automatic acceptance of students transferring from two year community colleges meeting minimum GPA requirements.

The BBC was launched in 2011 in an effort to get top students to self-identify a business majors upon entering USF as freshmen. This was intended to accomplish two key objectives. First, the entry requirements for freshman admission were much stricter than for transfers, meaning that four year undergraduate students were uniformly strong from an academic standpoint. Second, there was a move within the Florida State System to transform many of its two year community colleges into four year state colleges. Because business programs were among the most widely supported by these new, less expensive, state colleges, the number of third year transfers to USF was expected to decline in the long run. Increasing the MCOB's focus on supporting students for their full four years was part of the college's competitive response, and included both the BBC and BBN.

\section{Outcomes}

The $\mathrm{BBC}$ proved to be extremely popular and was oversubscribed each year. In order to make room for incoming freshmen, only a fraction of participants were allowed to remain the dormitories during their sophomore year. 
Informing Business School

\section{Informing Flows}

The principal informing flows appeared to be 1, 5 and 10 as described below (major flows in bold):

1. Institution to student: Supported through a wide array of special workshops and course offerings, as well as through enhanced advising.

2. Institution to research: Not a focus.

3. Institution to practice: Not a focus.

4. Research to practice (enabled): Not a focus.

5. Practice to students (enabled): Many events involving guests from practice and networking were arranged by the program.

6. Research to students (enabled): Not a focus.

7. Within institution (enabled): Not a focus.

8. Within research (enabled): Not a focus.

9. Within practice (enabled): Not a focus.

10. Within students (enabled): Fostering interactions between students that lived together was the principal goal of the BBC. The program also arranged for returning students to serve as mentors for incoming students. 


\section{Appendix D: Business Honors Program}

The Business Honors Program (BHP) at the MCOB at the University of South Florida is a multidisciplinary undergraduate program designed to attract and promote success for students passionate about rigorous coursework and research activities. The program blends the two with special residential, service, international, and applied learning opportunities found inside and outside of the classroom. The BHP brings together distinct features which include:

- Small classes that enhance learning

- Study abroad program geared toward understanding the global business environment

- Summer internship opportunities with top-rated business companies

- Comprehensive study in research and computational methods

- Research opportunities associated with the students' Honors thesis

- Corporate mentoring with industry leaders

- Personalized advising

Select incoming Bulls Business Community students are invited to apply during Spring Orientation. Eligibility requirements include:

- Acceptance into the Bulls Business Community

- Completed application form

- High School GPA of at least 3.50 (weighted)

- SAT score of at least 1140 (minimum 550 math) OR ACT score of at least 25 (minimum 24 math)

- Professional résumé

- Two academic recommendation letters

- Personal interview with the program director during orientation

The BHP curriculum is designed as follows:

Year One: Fall Term: General Education Core \& Honors I

Year One: Spring Term: General Education Core \& Honors II

Year One: Summer Term: International Study Abroad Experience

Year Two: Fall Term: Business Core Courses \& Research Methods

Year Two: Spring Term: Business Core Courses \& Computational Methods

Year Two: Summer Term: Internship Program

Year Three: Fall Term: Business Core Courses \& Major Coursework

Year Three: Spring Term: Business Core Courses \& Major Coursework

Year Three: Summer Term: Research Opportunities

Year Four: Fall Term: Major Coursework \& Honors Thesis

Year Four: Spring Term: Major Coursework \& MCOB Capstone Course

Service is a critical aspect of participation in the BHP. Each year, freshmen in the Business Honors Program have the opportunity to design a service learning project to aid community development. Additionally, Business Honors students take part in various outreach programs within and outside the country. Business Honors student projects include:

1. Noble Guides: Noble Guides is a non-profit volunteer service organization founded by Business Honors students from Cohort 2010. The project partners with organizations in the Tampa Bay area to providing academic and environmental assistance to communities. Some of the events they have participated are the Ronald McDonald 5K and work for Habitat for Humanity. 
Informing Business School

2. Sporting for Service - BHP: This service learning project, designed by students from the Business Honors Program Cohort 2011, organizes sports tournaments to benefit local organizations. Team proceeds from registration fees will go towards the organization that they are trying to support.

Business Honors students are also involved in various volunteer programs within and outside USF. Some of these inspiring programs include:

1. School Supplies for Afghan Children: This is an initiative by USF students geared towards providing school supplies to children in Afghanistan. They lend a hand to raising funds and donations of school supplies that are shipped to deprived communities in Afghanistan.

2. Nutre Hogar: This is a non-profit organization in Panama that treats, prevents, and fights against malnutrition in children. Students help raise funds collected from donations and selling cookies to help keep the organization afloat.

3. Bulls Service Break Program: One goal of the USF Bulls Service Break program is to raise awareness of social issues and injustice through education and intensive service learning experiences. This past year, students took time off during spring break to make a difference in New Orleans, Louisiana helping with hurricane Katrina relief efforts.

4. Play India: This is a non-profit organization whose main objective is to provide children located in small villages and slums in India with sporting materials such as soccer balls and cleats.

During Business Honors students' study abroad they learn and gain first-hand experience about the global business environment. On these trips, students take business courses at institutions located in their host country. Business Honors students have visited and studied in:

- Florence, Italy (with stops in Rome, the Vatican City, and Venice)

Students enjoyed the Italian cuisine, learned about the local customs and culture, and visited places of interest while taking business courses at the Florence Institute of Arts.

- Bratislava, Slovakia

During the trip to Slovakia, students visited the American Consulate and had the opportunity to visit Vienna, the Dell Factory, and many cultural sites.

- Seoul, South Korea

The South Korean experience introduced students to the Korean culture, language, local attractions, and the international business curriculum at Yonsei University.

- Lima, Peru

Peru offered an exciting opportunity to visit the mountain hills of Aguas Calientes, Machu Picchu, and the Catacombs, all while taking courses at the University of the Pacific.

- Beijing, China

First-hand experience of the Chinese culture and language as well as site visits to the Great Wall of China were among the many adventures in China.

\section{Outcomes}

Student success is the most important indicator of the program success and is highlighted in its outcomes. In addition to the examples of student service projects, volunteer programs and student study abroad trips above, the Business Honors students have achieved the following successes:

- $100 \%$ employment in their field of study upon graduation for the graduating cohorts in 2013-2014 and 2014-2015 academic years. 
- A significant portion of the MCOB "25 Under 25" (program described in this article) Awardees annually are members of the BHP. In 2014, 13 of the 25 awardees were BHP students. In 2015, 11 of the 25 awardees were BHP students.

- In the last two years, two BHP students received the USF university-wide Golden Bull Award (out of 40 awards "to undergraduate and graduate students who encompass the spirit of USF and have demonstrated its values").

- The USF Outstanding Undergraduate Student in 2015 was a MCOB BHP graduating senior.

- Over the last two cohorts every graduating senior had been selected for at least one internship and for study abroad.

\section{Informing Flows}

The informing flows for this activity are 1-3 and 6-10 as described below (major flows in bold):

1. Institution to student: Students receive additional training and have direct access to a Faculty Advisor. A Four-year classwork plan is part of the program that includes research and computational methods.

2. Institution to research: There is a required Honors Thesis that is overseen by a Faculty member in the general faculty

3. Institution to practice: Limited with respect to programs specific to the honors program. Nevertheless, honors students tend to be particularly involved in the MCOB programs intended to foster interactions with practice, including corporate mentorships (Appendix F), internship opportunities (Appendix P) and other enhanced learning activities, such as the Bulls Business Community (Appendix C).

4. Research to practice (enabled): None

5. Practice to students (enabled): There are multiple venues for direct interaction between students and practitioners that are integral parts of the program.

6. Research to students (enabled): Students and research-active faculty interact directly on projects of interest.

7. Within institution (enabled): Limited. Faculty serve on multiple committees and interact across disciplines. Business development and administration interact with students, faculty, and outside groups

8. Within research (enabled): Limited. Honors theses are presented in a colloquium environment attended by a cross-section of faculty. Faculty serve on multiple committees and interact across disciplines.

9. Within practice (enabled): Limited. Corporate mentors attend breakfasts and meetings with other mentors and students.

10. Within students (enabled): A diverse group of students is interviewed, is selected for inclusion, and shares common housing and a common curriculum within a cohort. 


\section{Appendix E: Case Study Initiatives}

The MCOB's case study initiatives have been underway for decades, growing in prevalence particularly since 2010. They have occurred in two largely distinct thrusts: case competitions and discussion case development.

\section{Case Competitions}

The MCOB case competitions are described as follows in the college's website:

Case competitions provide an opportunity for about-to-graduate undergraduates and top MBA students to challenge their skills and abilities as they analyze an ongoing business, consider current strategies and alternative courses of action, make strategic recommendations, and implement concrete steps to deal effectively with the problems/opportunities they have identified or have been asked to focus on by the case company's executives.

The college sponsors four competitions each year: undergraduate competitions in fall and spring semesters; an MBA competition in fall semester; and the Florida Intercollegiate Case Competition in spring semester. The Florida Intercollegiate Case Competition has included teams from USF, Florida State, the University of Florida, the University of Miami, Florida International University, Florida Atlantic University, and Rollins College.

\section{Background}

The concept for these competitions originated with MCOB faculty member Michael Bowen, who had first been acquainted with these competitions when he was asked to judge one while on the faculty a Notre Dame. When he first proposed the idea to the college in the late 1990s, the thendean had agreed to provide a modest amount funding and the first competition was held in 2001 . The case developed for that first competition by Bowen and a colleague was created from public sources and involved Pfizer, a large chemical and pharmaceutical company. Through another colleague, Bowen was put in contact with a senior manager of that company, who agreed to serve as a judge along with the panel of faculty members.

The first competition, and subsequent competitions, followed a format where students were given a case study and 24 hours to prepare presentations and answer questions about their analysis from a panel of judges. Over time, the competitions evolved in two important ways:

- The cases were increasingly developed in collaboration with the companies being described. By 2008, companies were largely responsible for creating their own cases and made presentations to kick off the competition. Later competitions even included visits to company sites as part of the competition process.

- The composition of the panel of judges became skewed towards practice, with faculty members increasingly playing a minor role.

From the second year, the college was hosting four of these competitions each year. When external funding was available, these competitions often offered participants substantial prize money.

\section{Outcomes of the competition}

Anecdotal responses from participants involved in the competition - both students and managers - suggested that the activity had a strongly positive impact. In Fall, 2015, Bowen and his colleagues began conducting an ongoing survey of past participants to assess their reaction to the experience. The preliminary results from the first 50 students, shown in Figure E.1, suggested the experience was highly beneficial. All mean values of the responses were between 1 and 2 on a 7 point scale where 1 indicated strong agreement with positive statements about the competition. 
4. Please rate the following statements about your case competition experience.

\begin{tabular}{|c|c|c|c|c|c|c|c|c|c|c|}
\hline$\#$ & Question & $\begin{array}{l}\text { Strongly } \\
\text { Agree }\end{array}$ & Agree & $\begin{array}{l}\text { Somewhat } \\
\text { Agree }\end{array}$ & $\begin{array}{l}\text { Neither } \\
\text { Agree nor } \\
\text { Disagree }\end{array}$ & $\begin{array}{l}\text { Somewhat } \\
\text { Disagree }\end{array}$ & Disagree & $\begin{array}{l}\text { Strongly } \\
\text { Disagree }\end{array}$ & $\begin{array}{c}\text { Total } \\
\text { Responses }\end{array}$ & Mean \\
\hline 1 & $\begin{array}{l}\text { I analyzed company and } \\
\text { industry performance data } \\
\text { (i.e. some form of business } \\
\text { analytics) to develop the } \\
\text { recommendations }\end{array}$ & 31 & 12 & 5 & 0 & 2 & 0 & 0 & 50 & 1.60 \\
\hline 2 & $\begin{array}{l}\text { I was able to network with } \\
\text { other students, professors, } \\
\text { or executives }\end{array}$ & 26 & 19 & 5 & 0 & 0 & 0 & 0 & 50 & 1.58 \\
\hline 3 & $\begin{array}{l}\text { My self confidence } \\
\text { improved as a result of this } \\
\text { experience }\end{array}$ & 31 & 9 & 5 & 5 & 0 & 0 & 0 & 50 & 1.68 \\
\hline 4 & $\begin{array}{l}\text { Creativity skills were } \\
\text { required to evaluate the } \\
\text { business problem }\end{array}$ & 38 & 7 & 5 & 0 & 0 & 0 & 0 & 50 & 1.34 \\
\hline 5 & $\begin{array}{l}\text { My team's proposed } \\
\text { solution was relevant to } \\
\text { the case organization's } \\
\text { business problem }\end{array}$ & 39 & 7 & 2 & 0 & 0 & 1 & 0 & 49 & 1.33 \\
\hline 6 & $\begin{array}{l}\text { Participating in the case } \\
\text { competition provided an } \\
\text { experience that will be } \\
\text { helpful to me in the } \\
\text { workplace }\end{array}$ & 39 & 6 & 3 & 2 & 0 & 0 & 0 & 50 & 1.36 \\
\hline 7 & $\begin{array}{l}\text { I got a sense of personal } \\
\text { accomplishment from my } \\
\text { participation in the case } \\
\text { competition }\end{array}$ & 38 & 7 & 4 & 1 & 0 & 0 & 0 & 50 & 1.36 \\
\hline 8 & $\begin{array}{l}\text { I would recommend the } \\
\text { case competition to a } \\
\text { friend or colleague }\end{array}$ & 41 & 5 & 3 & 1 & 0 & 0 & 0 & 50 & 1.28 \\
\hline
\end{tabular}

Figure E.1: Results of survey of 50 past participants in MCOB case competitions

The response to the competition from the companies involved was also strongly positive according to Bowen, although no effort had yet been undertaken to survey them. Bowen specifically recalled one executive that had stated words to the effect, "We got more out of this one 24 hour case competition than from a 6 month, $\$ 8$ million dollar engagement with a major national consulting firm." Several other subject companies have made similar comments on the value of their participation.

\section{Case Development}

Within the MCOB's Information Systems \& Decision Sciences department, several dozen discussion case studies have been developed relating to local businesses. These case studies have become central elements of the program's undergraduate and graduate capstone courses. Subsequently, the use of these cases expanded into the MCOB's MBA program, where they were used in both the required MIS course of the regular MBA and in the capstone course of the Executive MBA.

A central feature of the case development project was the involvement of case protagonists (i.e., the decision-makers featured in the case) in the early classroom discussions of the case. Where this occurrs (currently, in about half of all the discussions), students discuss the case for the first hour or so of the class, then the protagonists reflect on the discussion and reply to student questions. This creates an unusually interactive channel between students and practice.

\section{Background}

The systematic development of discussion cases within the MCOB began in 2011, when the Information Systems and Decision Sciences (ISDS) department received a $\$ 170,000$ grant from the 
Informing Business School

U.S. National Science Foundation to develop a case method undergraduate capstone course (Gill \& Ritzhaupt, 2013). In 2012, the first section of this class was launched with 11 new cases. During this semester, the case protagonist sat in on 10 of the 11 student case discussions. Subsequently the course was also offered in online form (Gill \& Mullarkey, 2015) and many of the cases developed were adapted for use in other programs.

In fall 2014, an IS\&DS instructor began requiring his MBA students to develop case studies as projects for the class. By fall 2015, nearly all the cases developed by the previous year's students were assigned for discussion within the same course. In parallel, in spring 2015, participants in the DBA program (see Appendix G) were required to develop case studies as the deliverable of a publication course. Several of these courses were scheduled for use during class sessions for the program's second cohort. These activities represent an unusual form of student-to-student informing flow.

\section{Outcomes of case development}

The initial learning outcomes from the transition of the undergraduate to the case discussion format were highly positive. As summarized in results of a Student Assessment of Learning Gains instrument shown in Figure E.2 (Gill \& Ritzhaupt, 2013, p. 82):

\begin{tabular}{|l|c|c|c|c|c|c|}
\hline \multicolumn{1}{|c|}{ Item } & $\mathbf{1}$ & $\mathbf{2}$ & $\mathbf{3}$ & $\mathbf{4}$ & $\mathbf{5}$ & Average \\
\hline $\begin{array}{l}\text { How helpful were the case studies and discussions in the following areas } \\
\text { 1=Not at all helpful, 2=A little, 3=Somewhat, 4=A lot, 5=A great deal }\end{array}$ \\
\hline Understanding MIS concepts & $0 \%$ & $5.71 \%$ & $11.43 \%$ & $37.14 \%$ & $45.71 \%$ & 4.23 \\
\hline $\begin{array}{l}\text { Understanding relationships between } \\
\text { concepts }\end{array}$ & $0 \%$ & $2.86 \%$ & $8.57 \%$ & $48.57 \%$ & $40 \%$ & 4.26 \\
\hline Understanding real world issues & $0 \%$ & $0 \%$ & $0 \%$ & $22.86 \%$ & $77.14 \%$ & 4.77 \\
\hline Improving my problem solving & $0 \%$ & $0 \%$ & $25.71 \%$ & $37.14 \%$ & $37.14 \%$ & 4.11 \\
\hline Improving my creativity & $0 \%$ & $0 \%$ & $42.86 \%$ & $14.29 \%$ & $42.86 \%$ & 4.00 \\
\hline Improving my analytical ability & $0 \%$ & $2.86 \%$ & $8.57 \%$ & $42.86 \%$ & $45.71 \%$ & 4.31 \\
\hline Improving my technical skills & $0 \%$ & $25.71 \%$ & $25.71 \%$ & $22.86 \%$ & $25.71 \%$ & 3.49 \\
\hline Improving my communications skills & $0 \%$ & $11.43 \%$ & $37.14 \%$ & $25.71 \%$ & $25.71 \%$ & 3.66 \\
\hline
\end{tabular}

Figure E.2: Results of SALG assessment from spring 2012. For this instrument, values of 3 or greater are generally considered positive indicators.

These results replicated nearly perfectly in subsequent offerings, including the online offering (Gill \& Mullarkey, 2015). In addition, two aspects of the class - using local companies as cases (4.54) and having protagonists sit in as guests (4.66) — scored exceptionally high.

In addition, the case development activities led to a series of outcomes that improved the university and the MCOB's visibility. These included:

- Three federal grants related to case writing: two from NSF, 1) $\$ 170,000$ for the undergraduate capstone work and 2) $\$ 300,000$ to develop cases for a cybersecurity capstone, and another from the Department of Defense for $\$ 58,000$. A faculty Fulbright was also awarded to support development of discussion case studies relating to eReadiness in South Africa.

- Publication of a book on the case method (Gill, 2011), along with several dozen case studies and the launch of the Journal of IT Education: Discussion Cases by the Informing Science Institute.

- Initiation of a conference track: Special Track on Case Studies and Methodologies (stCSM) special track of the Complexity, Informatics and Cybernetics conference in Orlando, now in its fifth offering (see http://www.iiisspring16.org/imcic/website/AboutConfer_stcsm.asp?vc=26) 


\section{Informing Flows}

The informing flows for this activity are 1, 3-5 and 9-10 as described below (major flows in bold):

1. Institution to student: Cases developed by faculty and other students are incorporated into course work.

2. Institution to research: Limited. While institutional support for the development of case studies would be considered a research activity in many disciplines (such as anthropology), there remains lively debate among business researchers as to whether or not case development can be characterized as business research.

3. Institution to practice: Through supporting case development, the institution strongly encourages faculty engagement with practice, an essential element of the case writing process.

4. Research to practice (enabled): The direct engagement of researchers with practice provides a significant opportunity for research insights to flow in both directions.

5. Practice to students (enabled): There is a direct interaction between students and practitioners that occurs when protagonists sit in on student discussions.

6. Research to students (enabled): Limited, depending upon the degree to which the discussion case study is considered a research artifact (see Item 2).

7. Within institution (enabled): Limited. Most cases developed thus far have emerged within a particular disciplinary area (such as MIS or entrepreneurship), and only occasionally move across departmentally offered courses.

8. Within research (enabled): None (subject to the Item 2 qualification).

9. Within practice (enabled): Limited. Use of these cases within EMBA and DBA programs encourages practice-to-practice engagement.

10. Within students (enabled): By their very nature, case discussions encourage student-tostudent informing. The development of case studies by one group of students that are later used by subsequent students provides an even more unusual activity supporting the same flow. 


\section{Appendix F: Corporate Mentor Program}

For more than 25 years, the USF Muma College of Business Corporate Mentor Program paired business students with mentors form the Tampa Bay business community. Mentors are business leaders who share common interests with the student, coach the student, and serve the student as a resource a broad range of guidance at a pivotal point in their academic career and professional development prior to entering the business world.

The Corporate Mentor Program includes workshops, seminars, dinners, interview training, and corporate networking opportunities that help students develop professionally and build the underlying skills necessary of a future business leader.

\section{Background}

Students in the Corporate Mentor Program are proven, successful juniors and seniors in the USF Muma College of Business in underrepresented demographics and first generation college students (first in their immediate family to attend college). Students must have a minimum of a 2.75 GPA and must be fully accepted into the USF Muma College of Business.

The selection process includes an application and interview and emphasizes a review of the student's campus and community service, prior leadership experience, willingness to participate actively with the mentor, and the ability to maintain academic goals for the duration of the mentorship.

Students and mentors meet monthly at the mentor's workplace. Students participate in the Professional Development Premiere course track that emphasizes interpersonal communications, "Dress for Success", "Branding Yourself", "How to Work a Room", and "Business Etiquette" to accelerate practical, pragmatic business skill development above and beyond the particular business discipline being pursued by the student.

Mentors are expected to invite mentees to ongoing conversations in informal, engaging discussions without office or academic distractions, frequently over coffee or a meal. Mentors should provide constructive supportive feedback and hold students to high standards to help them improve both professionally and personally. And, mentors should help students locate assistance from a broader business network and multiple mentors within the greater USF system, alumni, and business community.

Mentees are frequently afforded a partial scholarship to offset the cost of additional courses and time away from part-time jobs sometimes required of the program. Scholarship support comes from the Collier Student Success Center funding, TRowePrice, Nielsen, and the Tampa Bay Rotary among many sources and offers $\$ 100,000$ to mentees annually.

\section{Outcomes}

Several significant outcomes are cited by the Corporate Mentor Program including:

- More than 125 professionals and 70 firms regularly engage as mentors in the program.

- $100 \%$ of mentees are regularly offered jobs or graduate school in their discipline upon graduation.

- Mentees receive salaries that are typically $25 \%$ higher than those of comparable peers among USF graduates.

- The current Vice Chair of the USF System Board of Trustees is a graduate of the program. 


\section{Informing Flows}

The principal informing flows appeared to be 1, 3, 5, 9 and 10 as described below (major flows in bold):

1. Institution to student: The Professional Development Premier courses support the mentoring activity with a structured delivery of content and activities that allow students to practice business skills in the academic environment.

2. Institution to research: None

3. Institution to practice: The USF Muma College of Business identifies and selects mentors and establishes the practices essential to the conduct of good mentoring. The college also manages the selection of students and the pairing to the appropriate mentor. Mentors regularly offer observations on the needs of practice and provide insights on the additional training and development opportune for mentees.

4. Research to practice (enabled): None

5. Practice to students (enabled): The key informing flow is from practice-industry mentor to student. Mentors also report significant informing flows from students that improve mentors' understanding of the current generation's perspectives, outlooks, values, and ambitions.

6. Research to students (enabled): None

7. Within institution (enabled): None

8. Within research (enabled): None

9. Within practice (enabled): Local employers often cite positive experiences with USF Muma College of Business Corporate Mentor Program students in private and public forums to extoll the value of developing and maintaining a significant connectivity to the college.

10. Within students (enabled): Role playing and "Improv" (improvisation) exercises offer significant opportunities for students to "cross-pollinate" and inform each other in the conduct of the Professional Development Premier courses. 


\section{Appendix G: Doctor of Business Administration (DBA)}

The first cohort of the MCOB DBA program (Gill \& Mullarkey, 2015) was launched in 2015. The degree was intended to provide working professionals with the opportunity to earn a research-focused doctoral degree. Applicants to the program were required to have 12 years of professional experience with a minimum of 5 years at an executive or senior management level.

\section{DBA Design}

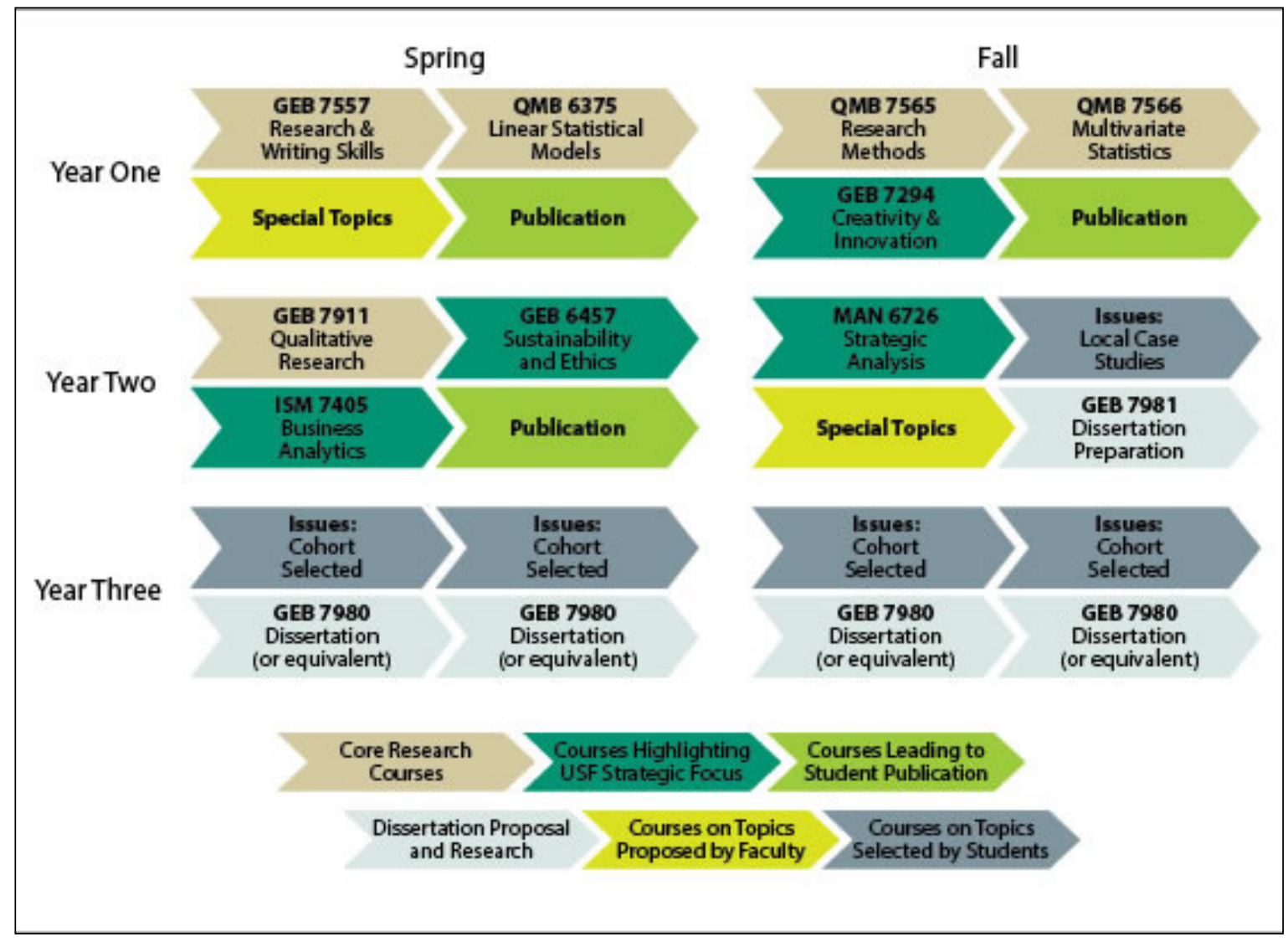

Figure G.1. Muma COB DBA Organization

The program design included the following key elements:

- 72 credits, delivered over 3 years.

- Cohort based. 10 weekend meetings each year, with substantial online content (10-15 hours/week) between meetings.

- First 2 years of the program consisted mainly of coursework, including the same research course requirements as the Ph.D. program. Final year of the program focused on dissertation (see Figure G.1 from the program's website).

- All coursework was intended to be interdisciplinary in its focus.

- Each of the first 3 semesters of the program included a "publication course", during which each participant was expected to produce a paper or case study suitable for submission to publication. 
- Participants were required to attend at least 3 academic conferences over the course of the program.

- Dissertation teams of 4 faculty formed at the end of the second year; each served as a committee for 4 individual participant dissertations.

- Dissertation requirement could be met in a variety of ways, including a traditional dissertation, a collection of papers, a project with a research-grounded white paper, authoring a research-grounded book, or through a portfolio of research-informed artifacts.

Further information on the launch of the program is described in a case study (Gill, 2014).

\section{Initial Cohort Characteristics}

The initial DBA cohort had 25 participants. Some of the key characteristics of the cohort are summarized in Figure G.2.

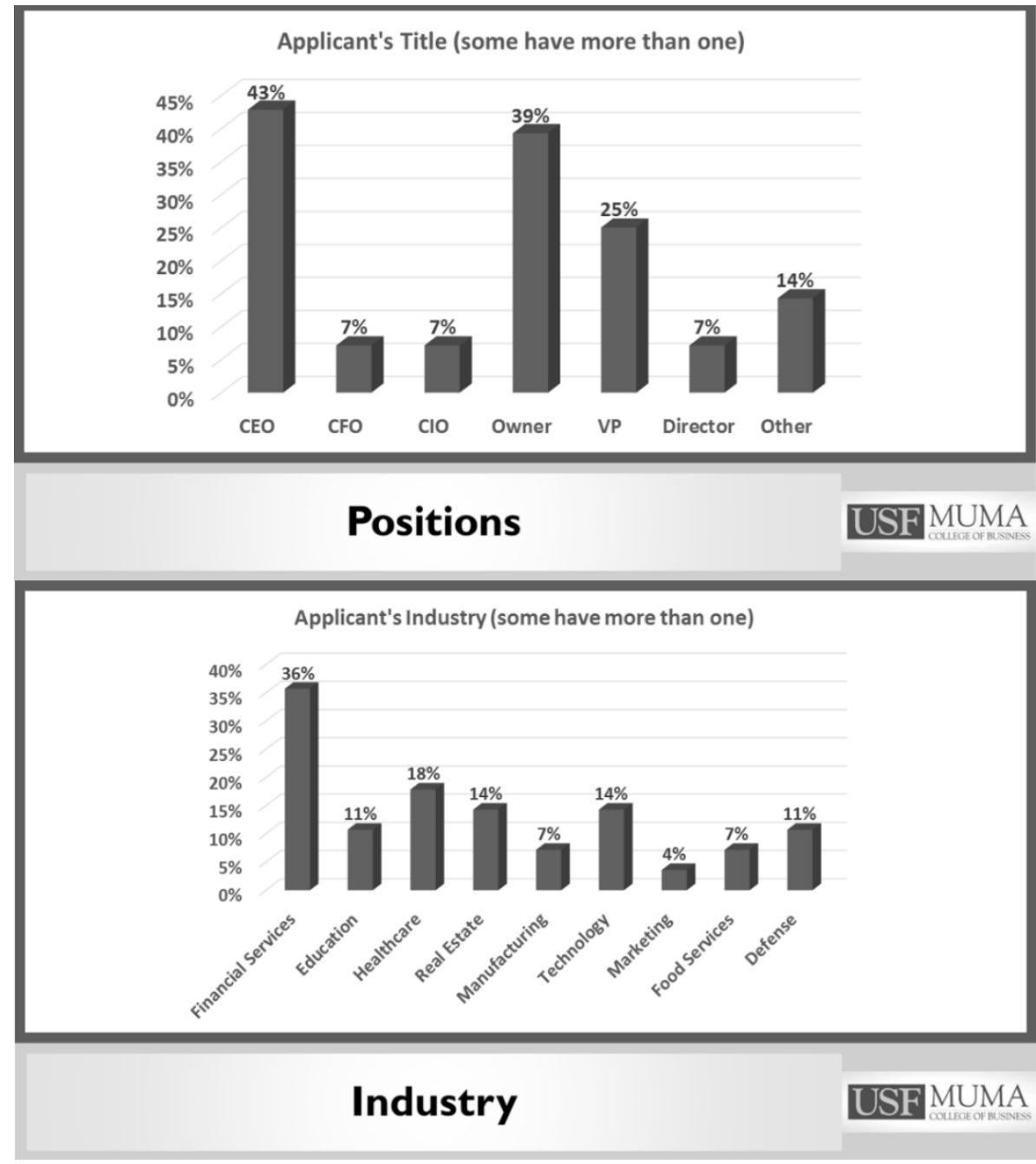

Figure G.2: Initial DBA cohort characteristics

\section{Informing Flows}

As noted in the body of the paper, the stated goal of the DBA program was to develop the research skills of its participants. The plan expectation was that these participants would then apply 
these skills to problems and decisions encountered in their own professional context. From an informing perspective, this effectively represented a merger of the practice and student stakeholder role, as shown in Figure G.3.

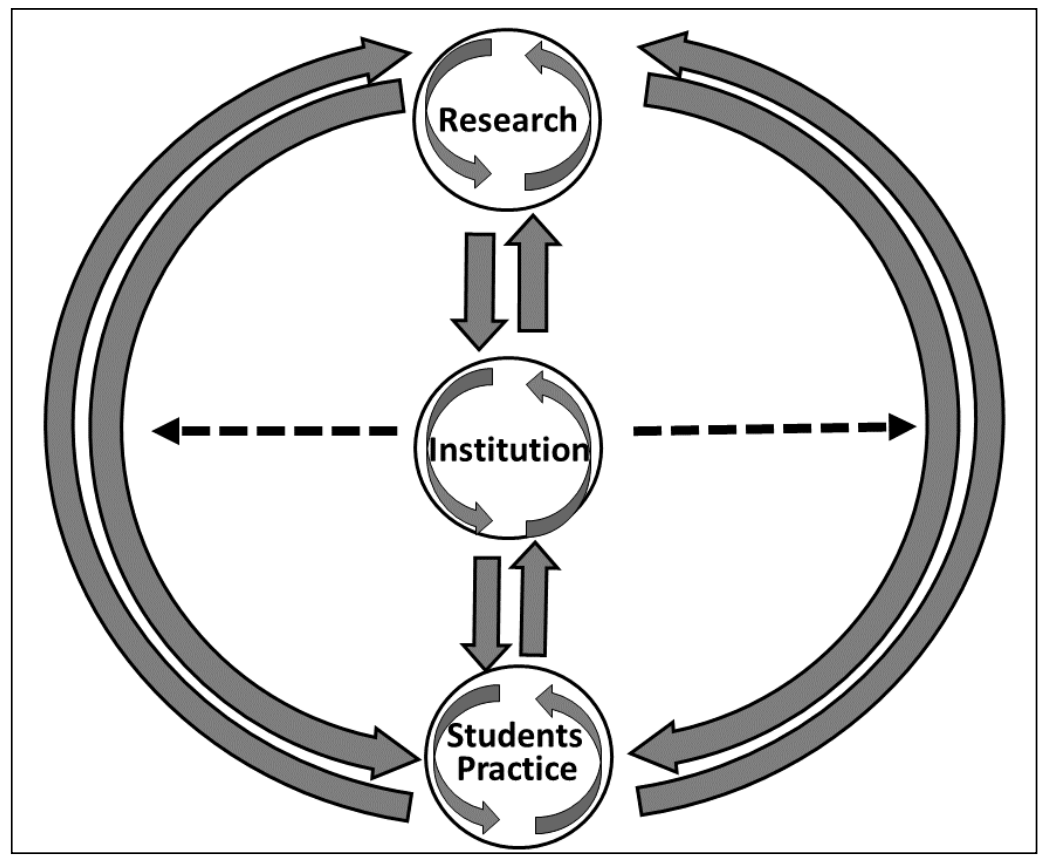

Figure G.3: Informing flows of the DBA program

\section{Outcomes}

Having been in operation for only a year at the time of this case, it would be premature to expect significant outcomes from the DBA informing patterns. Nevertheless, at the end of 2015, an online survey of the cohort just finishing its first year was administered. As shown in Table G.1, even by the end of their first year, a substantial fraction of the cohort (roughly $62 \%$ of the 21 that responded, an $84 \%$ response rate) indicated a high level of impact to their job from the program. Moreover, all of the respondents indicated that they expected what they learned to have a moderate or significant impact in the future.

Table G.1: Results of DBA Impact Study at the End of the First Year

\begin{tabular}{|l|c|c|c|c|c|c|}
\hline Question & $\begin{array}{c}1 \\
\text { Very } \\
\text { Little } \\
\text { Impact }\end{array}$ & 2 & 3 & 4 & $\begin{array}{c}5 \\
\text { A Great } \\
\text { Deal of } \\
\text { Impact }\end{array}$ & Mean \\
\hline $\begin{array}{l}\text { How much impact has participat- } \\
\text { ing in the DBA this past year had } \\
\text { on your business or employer? }\end{array}$ & $\begin{array}{c}2 \\
(9.5 \%)\end{array}$ & $\begin{array}{c}2 \\
(9.5 \%)\end{array}$ & $\begin{array}{c}4 \\
(19.0 \%)\end{array}$ & $\begin{array}{c}7 \\
(33.3 \%)\end{array}$ & $\begin{array}{c}6 \\
(28.6 \%)\end{array}$ & 3.62 \\
\hline $\begin{array}{l}\text { How much impact do you expect } \\
\text { participating in the DBA program } \\
\text { will have on your business or } \\
\text { employer in the future? }\end{array}$ & $\begin{array}{c}0 \\
(0 \%)\end{array}$ & $\begin{array}{c}0 \\
(0 \%)\end{array}$ & $\begin{array}{c}3 \\
(14.3 \%)\end{array}$ & $\begin{array}{c}6 \\
(28.6 \%)\end{array}$ & $\begin{array}{c}12 \\
(57.1 \%)\end{array}$ & 4.42 \\
\hline
\end{tabular}




\section{Informing Flows}

All informing flows appear to be well supported by the DBA program. Indeed, the merger of student and practice roles illustrated in Figure G.3 makes a number of them redundant (major flows in bold):

1. Institution to student: Students engage in classwork and interact directly with research faculty, who also review and mentor their work.

2. Institution to research: The program is research driven (albeit applied research) and faculty support student publication efforts.

3. Institution to practice: The fact that all the participants are practicing managers means that strong linkages are formed between the institution and practice. In fact, in the first cohort, one student was a member of the MCOB Executive Advisory Board and one was a Trustee of the university.

4. Research to practice (enabled): The nature of practitioner-students and the research focus of the program makes this linkage self-evident.

5. Practice to students (enabled): As illustrated in Figure G.3, the student and practitioner roles are joined. This effect is amplified by the discussion-oriented pedagogies employed and the structure of the student cohort, designed to build long term relationships.

6. Research to students (enabled): (Same as research to practice).

7. Within institution (enabled): The interdisciplinary nature of program content and dissertation committees fosters communications across departments.

8. Within research (enabled): The interdisciplinary nature of the program encourages communications across disciplines. This aligns with the expected multi-disciplinary nature of most business problems.

9. Within practice (enabled): The discussion focused pedagogy encourages communication across functions and industries, as does the diverse nature of the cohort (see Figure G.1).

10. Within students (enabled): (Same as within practice). 


\section{Appendix H: Entrepreneurship Programs}

The Entrepreneurship Programs consist of a collection of activities under the USF Center for Entrepreneurship, a multi-disciplinary center that is administratively located within the MCOB's Marketing Department. Among the center's initiatives are a Master of Science in Entrepreneurship and Applied Technologies (MS-EAT) program, a student incubator, a variety of competitions, a mentorship program, and a variety of certificate options. Annually, the center typically reaches about 500 graduate students (65\% of whom are international) through its MS and certificate programs and roughly an equivalent number of undergraduate students who minor in entrepreneurship.

\section{Background}

The Center for Entrepreneurship's Founding Director was Michael W. Fountain, whose titles crossed many disciplines and included MBA Director, Center for Entrepreneurship, John \& Beverley Grant Endowed Chair in Entrepreneurship Professor, Industrial \& Management Systems Engineering, and Professor, Department of Psychiatry \& Behavioral Medicine. The idea for the center originated in the late 1990 s, when a number of higher level administrators at USF, including provosts and deans, became concerned about the number of bright students being lost to entrepreneurial ventures. These concerns led to a three year development effort in which practicing entrepreneurs were interviewed and over 1000 CEO's were surveyed. Among the most intriguing results of this research were the following:

- Only one member of the typical firm's C-suite had a business degree, the CFO.

- While $20-30 \%$ of the participants had taken some graduate business courses, nearly none had gone on to get a degree. Instead, the respondents indicated that however great the faculty teaching in these programs, the information being conveyed was nearly always out of date. The respondents also felt that few of their professors had ever had to meet a payroll or deal with typical small business problems, such as disputes between partners.

When asked to specify what a program "should" look like, a consensus emerged that the content mix should be along the lines of:

- $40 \%$ business topics.

- $40 \%$ engineering, such as new product development, quality control and technology management.

- $20 \%$ other topics, such as legal issues and contracts.

The original MS-EAT program design, therefore, followed these lines, with 10 courses covering the respective topic areas in a 4-4-2 mix.

Five students enrolled in the first cohort. In its early years, roughly $10 \%$ of the students were international.

\section{Degree and Non-Degree Programs}

\section{MS-EAT}

The current USF MS-EAT program typically enrolls 100-130 students in each cohort. In addition, the balance of U.S-international students has changed dramatically, from its original $10 \%$ to around $65 \%$ international in recent years. While the degree still requires 10 courses (30 credits), the presence of so many international students required changes to the courses, since many areas (such as small business financing) vary significantly from region to region. As a consequence, the program now consists of 5 core courses and 5 electives, providing students with greater flexibility 
in tailoring their curriculum. These courses come from many different colleges in the university, including business, medicine, engineering, arts and sciences and sustainability.

Fountain estimated that only about $25 \%$ of MS-EAT students are from business disciplines. The remainder came from a range of backgrounds too diverse to characterize-."From anthropology to zoology" as he described it. Many of the participants already had advanced degrees, including M.D.s and J.D.s.

Throughout the curriculum, engagement with practice was continually engaged. In an interview conducted as part of the study, Fountain characterized the philosophy as similar to that of the last two years of U.S. medical school, where a systems-based clinical approach is typically taken. He indicated that there are three prongs to this approach:

1. Drawing upon content

2. Peer-to-peer learning

3. Active supervision by domain experts

In the case of the MS-EAT, these experts include participants from many general and specialized industry groups, including the local CEO Council, Chamber of Commerce, Service Core of Retired Executives (SCORE), Tampa Bay Technology Forum, BioFlorida, Medical Devices Manufacturer's Council, and many others.

\section{Certificate programs}

In addition to its flagship degree program, the center offered a variety of graduate certificate programs. These programs consisted of four 3-credit courses and were matched up with a variety of different degrees, including the MBA, MS in engineering (across many areas), MPH, MD, MA in Sustainability, and many other programs. These programs served up to 500 students each year.

\section{Undergraduate programs}

The center provided three undergraduate minors, each serving a different constituency. These were as follows:

1. Business

2. Industrial Engineering and Business

3. Non-Business/Non-Industrial Engineering Majors (5 courses instead of 4)

Unlike the graduate courses, which were all conducted face-to-face, the undergraduate courses included a large percentage $(70 \%)$ of online delivery.

Around 1000 students were enrolled in these courses.

\section{Supporting Activities}

Supporting the center's course delivery were a large number of non-classroom activities. These included some for-credit offerings, such as internships and practicums. They also included many opportunities to acquire skills through active engagement with practice and other students. These were the focus of the current paper.

\section{Competitions}

The center hosted a number of different student competitions, each of which were judged by representatives from industry. The center's website listed four of these: 


\section{Fintech Business Plan Competition}

The competition provides USF students a chance to receive critical assessments and reviews of their new businesses with professional guidance on strategies and tactics to successfully fund and grow new ventures.

\section{Innovative Technology Challenge}

Held every spring, the Innovative Technology Challenge is a semester-long interdisciplinary class where teams of students are immersed in creating, thinking, and cultivating new product prototypes, along with commercialization and marketing strategies, for specific industries.

\section{ACG Cup}

The ACG Cup is a case study competition designed to give students from leading graduate programs across the country real world experience and invaluable insights into mergers and acquisitions, investment banking, financial advising, and private equity. The ACG Cup at USF is hosted by the Center for Entrepreneurship and is open to all College of Business graduate students.

\section{FL Healthcare Innovation Pitch Competition}

The annual State of Florida Healthcare Innovation Pitch Competition is held at the University of South Florida in the Spring Term. This state-wide competition is open to undergraduate, graduate, and healthcare students from Medical, Dental, Veterinary, Pharmacy, Public Health, and Nursing schools from across the State of Florida.

In addition to these hosted competitions, student participants in the various programs were encouraged to enter other college-wide competitions, such as the case competition (described in Appendix E).

\section{Student incubator}

The Student Innovation Incubator provided services, such as office space, 3D printing, meeting rooms, consulting, legal services, and training, for student initiated businesses. Unlike many incubators, these businesses needed to be incorporated and needed to make it through a highly selective screening process in order to be included. Fountain estimated that about 40 companies had been hosted at the incubator out of around 200 applications.

\section{Mentorship}

Virtually any student in the various programs offered by the center could request, and be assigned to, a local business mentor. These relationships were usually set up to last for one year, and mentors and mentees were required to interact at least twice a month, at least one of the meetings being face-to-face.

\section{Outcomes}

Since 2010, the USF Entrepreneurship program has been ranked as one the top 25 programs in the U.S. by the Princeton Review. In 2015, it was ranked number 11 on that list.

In 2014, the center conducted a study in which they contacted their alumni base. Based on the results, Fountain indicated that the occupations of the program's 220 alumni broke down along the following lines:

- $\quad 140-150$ had gone on to found one or more businesses. 
- 20-30 had gone on to join entrepreneurial support organizations, such as venture capital firms.

- 20-30 had gone on to work in the new business development areas of larger firms, often with titles such as Chief Innovation Officer.

- 15 or so had gone on to acquire doctoral degrees and become academics.

\section{Informing Flows}

Virtually all the informing flows involving either students or practice were highly active in the various entrepreneurship programs. The principal informing flows appeared to be 1, 3, 5, 7, 9, and 10 as described below (major flows in bold):

1. Institution to student: Students engage in classwork and interact directly with research faculty, who also review and mentor their work.

2. Institution to research: Limited. The academic research activities of the center appeared to be secondary to its efforts towards practical problem solving.

3. Institution to practice: Virtually every program and activity hosted by the center involved practicing entrepreneurs and managers.

4. Research to practice (enabled): Limited. Conveying academic research to and from practice did not appear to be a major objective of the center, which strongly emphasizes applied research.

5. Practice to students (enabled): Virtually every student activity-including course work-involved participation by practice.

6. Research to students (enabled): Limited, similar to research to practice.

7. Within institution (enabled): The interdisciplinary nature of the programs required continuous interaction across college and disciplinary boundaries.

8. Within research (enabled): Not a principal focus.

9. Within practice (enabled): Many program activities, such as competitions and the incubator, involved bringing practicing managers and experts from diverse backgrounds together.

10. Within students (enabled): The strong peer-to-peer emphasis of the program and the need to form multi-functional teams encouraged high levels of communications between students. 


\section{Appendix I: Faculty Externships}

Faculty externships are designed to match faculty with specific businesses for a six month period. The goal is a synergistic opportunity for the business to receive a consultative effort from a member of faculty with research interests in the topic of interest to the business. The topic of interest may include a search for solutions to a particular business problem, an innovative product or service design and introduction, a critical business decision, or any other critical business issue requiring a methodical inquiry and investigation best conducted by a qualified researcher. The business receives the research effort at no cost. The researcher receives unique access to data and key research questions and is afforded a course release for the six months. The college strengthens the bond between the institution and the business community and meets a criterion that is becoming increasingly important to accrediting agencies.

\section{Background}

The college and many members of the research active faculty pursue relationships with business in order to gain access to interesting data and challenging problems that can advance existing streams of research and open new avenues for research contribution to the body of academic work. Many businesses face sticky, wicked business problems and decisions that could benefit from a rigorous research approach but lack the talent, time, and/or methods to conduct the research required. The faculty externships offer a no-cost, low risk opportunity for business to engage one or more research faculty in exchange for access to people, processes, and data that can inform research. The faculty gain an avenue for course release that frees them for the conduct of research that advances their scholarship and potentially fulfills needed requirements for tenure.

\section{Outcomes}

The key outcomes from Faculty Externships include research that is relevant to practice and to academia, resolution of real business issues that benefit the business community, compliance with accreditation requirements, and the introduction of real business issues into the future curriculum as faculty shares research within the classroom.

Informal Faculty Externships currently exist without the formal structure of a sanctioned course release and are not currently tracked with rigor. The associate dean and department chairs are working to formalize the structure, organization, and measurement of outcomes for this effort at practice inspired research with impact.

\section{Informing Flows}

The principal informing flows appeared to be 1, 2, 3, 4, 8, and, potentially, 9 as described below (major flows in bold):

1. Institution to student: Not directly. Ideally, this informing flow occurs as researchers introduce their research to students in the construction and delivery of new, innovative curriculum.

2. Institution to research: Limited. This informing flow occurs as researchers publish research conducted in conference proceedings and journals.

3. Institution to practice: This informing flow occurs in both directions as practice informs the faculty of research worthy business issues and as faculty bring to bear research methods that lead to inquiry, and potentially solutions, that inform the business(es) involved. 
4. Research to practice (enabled): This informing flow may be excited by the co-authoring and co-investigation of key research questions by the combined activities of practitioners and researchers.

5. Practice to students (enabled): None

6. Research to students (enabled): None

7. Within institution (enabled): None

8. Within research (enabled): Limited. Practice inspired research has the ability to extend research streams in new and interesting ways that can lead to further research across the research community.

9. Within practice (enabled): Limited. Rigorous research that leads to new and novel ways of defining and resolving critical business issues effecting an industry and/or generalizable to multiple businesses will inevitably inform from practitioner to practitioner.

10. Within students (enabled): None 


\section{Appendix J: Florida Center for Cybersecurity}

The Florida Center for Cybersecurity $\left(\mathrm{FC}^{2}\right)$ was created by the Florida Legislature under the direction of the Florida Board of Governors to establish a center of cybersecurity leadership that would:

- Position Florida as the national leader in cybersecurity and its related workforce through education, community engagement, and innovative, interdisciplinary research;

- Create thousands of new high-paying jobs in the state's cybersecurity industry;

- Serve as a facilitator for cybersecurity education - providing degrees, certificates, and training while contributing to Board of Governors priorities and encouraging students in non-IT majors to obtain industry-recognized cybersecurity specializations to enhance employability and wages upon earning their desired degrees;

- Enhance Florida's cybersecurity workforce, including reintegrating military veterans by utilizing their specialized skills and training;

- Act as a cybersecurity clearinghouse for statewide business and higher education communities - sharing knowledge, resources, and training opportunities to help mitigate cybersecurity threats, and optimizing investment to eliminate unnecessary duplication;

- Attract new financial, healthcare, transportation, utility and defense companies to Florida.

The $\mathrm{FC}^{2}$ partnered in the co-creation of the Masters in Cybersecurity and supported the outreach efforts that include the annual $\mathrm{FC}^{2}$ Conference. Faculty in the college are competing for cybersecurity grant funding from the $\mathrm{FC}^{2}$ in collaboration with Principle Investigators from sister institutions in the Florida State University System.

\section{Background}

The $\mathrm{FC}^{2}$ located on the campus of USF is a statewide initiative that is charged with developing a collaboration among all twelve State University Systems (SUS) institutions of higher education and private partners for the development of cybersecurity as a central pillar of Florida's economic future.

The $\mathrm{FC}^{2}$ included initiatives in cybersecurity education, research, outreach, and information dissemination. The $\mathrm{FC}^{2}$ worked with USF and the Muma College of Business to create a crossdisciplinary Masters in Cybersecurity and an offering of industry recognized security certifica-

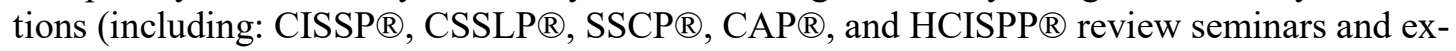
ams).

The FC ${ }^{2}$ established the competitive FC $^{2}$ Collaborative Seed Grant Program to fund research teams focused on projects that align with the $\mathrm{FC}^{2}$, s strategic priorities and that have the potential to attract additional outside funding. The applicants must be eligible to be Principal Investigators (PI) for external grants and each team must have investigators from at least two different SUS institutions.

A significant outreach effort annually is the $\mathrm{FC}^{2}$ Conference held in October during the National Cybersecurity Awareness Month. The conference is a two day event that includes keynote presentations, participant workshops and seminars, an industry trade-show, and one or more cyber-wargame events. Participants are drawn widely from local, state, and federal governments and agencies, industry partners, and student, faculty, and staff of the Florida SUS. Presentations at the most recent conference included the following:

Kevin Nesbitt, Unit Chief- Enterprise Security Operations Center, FBI Innovation in Critical Threats - Insider Negligence, Government 
Deborah Johnson, Vice President, Information Security, Jacobs Engineering

Innovation in Critical Threats - Insider Negligence, Industry

Dr. Tommy Gardner, Chief Technology Officer, Jacobs

Cyber Innovation Center - What, Where, When and Why

John Felker, Director, NCCIC

Vision and Strategic Direction for the National Cybersecurity and Communications Integration Center

Dr. Shuyuan Mary Ho, Assistant Professor, School of Information, Florida State University

Innovation in Critical Threats - Insider Negligence, Academia

\section{Outcomes}

Key outcomes include:

1. A $\$ 300,000$ grant from the National Science Foundation was awarded in 2013 to a PI from the Muma College of Business to support the development of discussion case studies dealing with cybersecurity decision making.

2. Approximately $\$ 500,000$ was awarded to twelve research teams in the first year of grant funding, and an additional $\$ 500,000$ was set aside for funding in the second year with award announcements in Q1 annually.

3. The annual conference was exceptionally well attended with over 500 delegate participants from state and nationally recognized leaders in cybersecurity at the industry, governmental, non-governmental, and educational levels.

4. USF graduated the first cohort of the MS Cybersecurity in 2015 and enrollment continues to grow.

\section{Informing Flows}

The principal informing flows appeared to be 1, 2, 3, 4, 7, 8, and 9 as described below (major flows in bold):

1. Institution to student: The principle informing flow is from faculty to master's level students in the MS Cybersecurity degree program.

2. Institution to research: Grant funding is designed to promote innovative cybersecurity research that informs practice and academia.

3. Institution to practice: Grant funding is designed to promote innovative cybersecurity research that informs practice and academia. The outreach conference is designed to provide a unique forum within the state for the collaborative dissemination of cybersecurity information and innovations.

4. Research to practice (enabled): The conference and funded research are designed to engage the broader research community to inform Florida cybersecurity businesses as industry partners in the investigation of cybersecurity topics of interest.

5. Practice to students (enabled): Limited, although the eventual publication and use of the NSF-funded case studies may further support this channel.

6. Research to students (enabled): Limited, although many of the Center's research grant opportunities are available to students.

7. Within institution (enabled): The cybersecurity degree programs are multi-disciplinary and co-created across the colleges of business, engineering, and criminology. The con- 
ference is multi-disciplinary and included participants from all represented colleges and all of the SUS institutions.

8. Within research (enabled): Grant funding and the conference actually facilitated the inclusion and cross-pollination of researchers from across the cybersecurity research landscape.

9. Within practice (enabled): The conference and certificate programs facilitated unique partnering and dialogue opportunities among industry partners directly.

10. Within students (enabled): Limited. Online degree program at the Masters level only provides very little informing among and between students. 


\section{Appendix K: Muma Journals}

The USF Muma College of Business launched two open access journals at the start of 2016. The first of these, the Muma Case Review (MCR), was intended to serve as a repository of discussion cases across all business disciplines. The second, the Muma Business Review (MBR), was intended to serve as an outlet for research-informed publications written in a manner that was accessible to practice.

\section{Background}

The decision to launch two journals was largely driven by the activities of the new DBA program (see Appendix G). In spring 2015, the participants had their first publication course, for which they developed a discussion case study using a template originally developed for the Journal of IT Education: Discussion Cases, published by the Informing Science Institute (ISI). The quality of the cases developed was unexpectedly high but - with the exception of cases in the IT area-it was recognized that appropriate outlets for timely publication were not available. For this reason, the dean and DBA program's Academic Director decided to launch a new journal whose mission was to publish discussion cases across all the business disciplines. At the same time, the need was recognized for an outlet that would publish the product of subsequent publication courses; these focused on practice-centered research articles rather than discussion cases. Thus, a second journal intended to fill that role was launched at the same time.

The decision to make both journals open access was driven both by the lack of open access case studies and practice-focused journals and by the DBA program's desire to partner with the ISI, who supplied the same manuscript submission and peer review system used for its own family of journals. Both journals began their initial volumes in 2016. The MCR's issues would be online only, with occasional special issues of related cases being published in print form. Its principal audience was intended to be faculty members and students who would use the cases in classroom or online facilitated discussions.

The MBR was designed to follow the pattern of ISI's family of journals, with articles published online upon acceptance and printed volumes being released at the end of each year. Its principal audiences were intended to be twofold: practicing managers interested in business research and members of the research community interested in research applied to practice. Realistically, in its early stages the expectation was that it would be of greatest interest to participants in the USF and other DBA programs - i.e., individuals straddling both communities.

Both journals planned to encourage submissions from researchers throughout the world. During their launch year, however, the main source of content was expected to be the students and faculty of the USF DBA program.

\section{Outcomes}

Early in their first year of operation, it was premature to assess the outcomes of the two journals.

\section{Informing Flows}

Because the MCR and MBR have fundamentally different missions and intended audiences, the informing flows supported or enabled by the two are correspondingly different. Because its missions is to serve as an outlet for quality business discussion case studies, the MCR's flows are, effectively, the same as those associated with the case study initiatives (Appendix E).

The intended informing flows for the MBR journal are 1-6 and 10 as described below (major flows in bold): 
Informing Business School

1. Institution to student: By launching the MBR and by encouraging both students and faculty to contribute, the journal was intended to serve as a means through which the institution could support and communicate with the student, practice, and research communities.

2. Institution to research: See item 1.

3. Institution to practice: See item 1.

4. Research to practice (enabled): The MBR's mission is the publication of research written in a form that is accessible to practice, making this path of communications a key objective.

5. Practice to students (enabled): With its initial focus on seeking contributions from executive programs, the student to practice pathway is supported. Somewhat less prominent, the MBR provides an "Opinion" template intended to serve as a venue through which practitioners might offer research ideas to students and other MBR readers.

6. Research to students (enabled): To the extent that the MBR succeeds in gaining readership and a broad submissions base, the critical role expected to be played by student researchers would make this a significant informing channel.

7. Within institution (enabled): Limited. With its multidisciplinary focus, it is possible that the MBR's articles might encourage some communications across departments.

8. Within research (enabled): Limited. With its multidisciplinary focus, it is possible that the MBR's articles might encourage some communications across disciplines.

9. Within practice (enabled): Not a major focus.

10. Within students (enabled): By seeking to position the MBR as a suitable outlet for executive doctoral programs around the globe, the expectation was that it would support communications between the students enrolled in different programs. 


\section{Appendix L: Ph.D. Program}

USF's Muma College of Business PhD program primarily prepares its graduates for careers as college and university professors, though some graduates have pursued careers in industry and government. Doctoral students develop skills through working closely with faculty in research seminars, on research projects, and teaching.

The goal of the $\mathrm{PhD}$ program is to create intellectual capital and produce graduates who are competitive for tenure track faculty roles at Tier 1 research institutions of today and tomorrow.

The $\mathrm{PhD}$ in Business Administration offers research concentrations in Information Systems \& Decision Sciences, Marketing, Accounting, and Finance.

\section{Background}

The $\mathrm{PhD}$ program requires a minimum of 90 credit hours beyond the bachelor's degree is required. This includes 21 credit hours of dissertation. A minimum of 45 credit hours of coursework must be completed at University of South Florida. Students will take a minimum of 9 credit hours from one or more fields outside the concentration department. These courses will be selected to complement the concentration and may include courses from outside the Muma College of Business.

A student may satisfy foundation course requirements in any of the following ways with approval of the student's program committee.

- By completing an undergraduate degree in business at an AACSB accredited institution, with an average of "B" or better in the last 60 credit hours, no more than five years prior to admission to the doctoral program.

- By completing an MBA degree at an AACSB accredited institution, no more than five years prior to admission to the doctoral program.

- By completing a graduate course (two credit hours or more) with a grade of " $\mathrm{B}$ " or better, in each of the functional areas: accounting, finance, information systems, management, and marketing. All graduate level courses at the 6000 level or above, with the exception of specific "tool" courses (for example, statistics), will count toward this requirement.

- By successfully petitioning the Doctoral Program Committee to accept previous academic work (for example, a specialized masters program in business or a degree granted more than five years ago) in fulfillment of all or part of this requirements.

Core courses are required of all students in the program. The college will waive a course only if the student has passed the same or equivalent course with a grade of " $\mathrm{B}$ " or better within the preceding five years. The two core areas are economics and research/quantitative methods.

The economics requirement can be met by completing two graduate level courses with a grade of " $\mathrm{B}$ " or better. A one-credit research skills course is also required. The quantitative and statistical coursework is to be determined by the student's advisory committee in consultation with the student. A three-course series is required. Students are also required to take an additional quantitative or statistics elective approved by the advisory committee.

Admission to the $\mathrm{PhD}$ program is considered highly competitive for a limited number of positions each academic year. A limited number of graduate assistantships are available to doctoral students. The assistantships pay approximately $\$ 20,000$ for twelve months, plus partial tuition waivers. Decisions regarding assistantships are made on a competitive basis.

Applicants must demonstrate high levels of success in previous academic work and a competitive score on the Graduate Management Admissions Test (GMAT). Students may apply after earning 
Informing Business School

a bachelor's degree. However, a master's degree is preferred. In order to be considered for admission, applicants must provide the following items:

- University application • Transcripts • GMAT scores • TOEFL scores (if applicable) • Résumé • Statement of goals and objectives $\bullet$ Three recommendation letters

\section{Outcomes}

The PhD program is measured almost exclusively on the placement of graduates in prestigious universities worldwide with recent graduates attaining faculty positions at:

- Texas A \& M • Virginia Tech • Syracuse University • Baylor University • New York University at Oswego $\bullet$ Florida International University $\bullet$ Georgia State $\bullet$ University of Arkansas - Little Rock $\bullet$ Kent State University $\bullet$ North Carolina Stat $\bullet$ HEC Montréal $\bullet$ California State University, Fullerton • Hofstra University • University of Wisconsin at Eau Claire • Wake Forest University • Indian Institute of Technology Kanpur $\bullet$ Northern Illinois University $\bullet$ University of North Dakota

Several recent graduates have received notable recognition for their doctoral research including:

- In 2014 the Academy of Marketing Science awarded Marketing doctoral student Nazuk Sharma with the Jane K. Fenyo Award for the best paper by a doctoral student.

- IGI Global selected ISDS doctoral student Kaushik Dutta as a winner of the Seventh Annual Excellence in Research Journal Award.

An additional highly desired outcome is presentation and publication of doctoral research in acclaimed academic conferences and journals, frequently in combination with research active faculty advising doctoral students.

\section{Informing Flows}

The principal informing flows appeared to be 1,2,6, and 8 as described below (major flows in bold):

1. Institution to student: A critical informing flow is the transmission and practice of rigorous research methods from the faculty to the $\mathrm{PhD}$ student. This informing flow occurs through coursework and through mentoring relationships established between research active faculty advisors and the PhD student. In rare case, usually involving more experienced $\mathrm{PhD}$ students, informing flows may occur from the student to the faculty generally involving a practice inspired line of investigation.

2. Institution to research: Co-authored articles that are accepted in academic conference proceedings and journals inform research and lines of research under investigation in the doctoral student's field are usually identified by the faculty advisor to inform the $\mathrm{PhD}$ topic of interest.

3. Institution to practice: Non-existent in most $\mathrm{PhD}$ research.

4. Research to practice (enabled): Non-existent in most $\mathrm{PhD}$ research.

5. Practice to students (enabled): Limited. Information flows between practice and student may be engaged with the more applied $\mathrm{PhD}$ disciplines and where original research involving actual field experiments and action research are conducted during the course of the $\mathrm{PhD}$. The degree to which these activities are present depends heavily on the candidate's field of study. 
6. Research to students (enabled): $\mathrm{PhD}$ students are required to conduct extensive literature reviews to gain knowledge from existing research in their topic of interest. PhD students are also encouraged to present in-progress and completed $\mathrm{PhD}$ research to academically prestigious conferences and journals in their area of research specialization.

7. Within institution (enabled): As a consequence of the specialization associated with most $\mathrm{PhD}$ research, this flow within the institution of active $\mathrm{PhD}$ research is generally not actively pursued.

8. Within research (enabled): The $\mathrm{PhD}$ doctoral research as published or presented within the research community may lead to a line of inquiry and results that further inform researchers - generally within the area of concentration of the dissertation.

9. Within practice (enabled): Generally this flow within practice of active $\mathrm{PhD}$ research is non-existent.

10. Within students (enabled): Informing flows between $\mathrm{PhD}$ students are not emphasized in the program and informing flows between $\mathrm{PhD}$ students in different areas of concentration are nearly non-existent. 


\section{Appendix M: Practice Centers}

The USF Muma College of Business uses Practice Center Projects to give students new skills and experiences investigating and resolving "real world" problems facing business partners. A Practice Center Project offers companies, typically in the local business community, the opportunity to attack a specific problem over a sixteen week period with a team of 2-4 students (frequently at the Masters level) supervised by a member of faculty. The problem is typically a "one-off" project where students work in teams and bring to bear their expertise (digital marketing, software programming, data analytics, etc.) to address a problem facing the company where company personnel do not have either the time or the expertise (or both).

\section{Background}

The Practice Center Project inevitably offers students the ability to address complex, rich problems affecting a business while working directly with practitioners at the host company. Each project is supervised by a member of faculty and at least one representative of the projectsponsoring company.

The students conduct the project work extra-curricular to their coursework and are compensated for the work from the grant provided by the practice center project sponsoring company. The grant also covers the cost of the faculty support and USF Muma College of Business overhead.

Project selection is based upon sponsor company business need and specific learning objectives for the students. Business partners identify a need to the college either directly with a department (often due to a prior connection to a member of faculty in that department) or to the USF Muma College of Business Director of Internships \& Practice Center Projects. Student participants must be USF Muma College of Business students in good standing and are selected based upon competitive GPA, required skill sets, and ability to commit to about 10 hours per week in addition to their curriculum and outside work requirements.

Practice Center Projects were begun in the Information Systems Department as business leaders identified needs for technical problem solving and were faced with a dearth of skills or resource at their organization to work on specific problems. They have since expanded to each of the departments in the college as a means of formalizing the structure and conduct of practicesponsored student project work.

\section{Outcomes}

Business partner sponsoring companies benefit through access to top-quality, highly skilled students that are able to investigate problems and create solutions while leveraging the expertise of faculty members.

Companies are also able to engage and observe students perform projects for future consideration of full-time employment thereby reducing the cost and a part of the risk of the recruiting process.

Participating students benefit from applying their knowledge and skills to a "real world" problem in a relatively low risk environment (no one is going to get fired for making a mistake, for instance) with the support of trusted members of faculty.

Faculty are able to apply their knowledge to problems and maintain currency in their practice focused skills. They are also able to observe and learn about current problems and issues in industry, which they can bring to the classroom and to their research. In some cases, a Practice Center Project can lead to a continuing relationship between the sponsoring company and a member of faculty that leads to more Practice Center Projects and/or research opportunities. 


\section{Informing Flows}

The principal informing flows appeared to be 1, 3, 5, 7, 9, and 10 as described below (major flows in bold):

1. Institution to student: By design, the Practice Center Project is informed by a member of faculty who provides project oversight and who facilities student learning and execution of work during the project.

2. Institution to research: None

3. Institution to practice: Practice Center Projects tend to be an exceptional vehicle for increased interaction and informing between sponsor company representatives and members of faculty. Each tends to learn more about the skills and capabilities of the other.

4. Research to practice (enabled): Limited, depending upon the nature of the project. In some projects, research organized by the faculty supervisor or students plays a major role, although most of that research tends to be applied.

5. Practice to students (enabled): The primary focus of the Practice Center Project is the ability of the sponsoring company to inform students and the ability of the students to use their skills, many learned in their discipline at the USF Muma College of Business, to inform the company through the investigation and resolution of specific problems.

6. Research to students (enabled): Limited. See Item 4.

7. Within institution (enabled): Limited, at this point there is no forum to share the learnings student and faculty receive from these projects with a wider audience either at the department or college level so it is all "word of mouth" informing that occurs by exception.

8. Within research (enabled): None

9. Within practice (enabled): Limited. Local employers often cite positive experiences with USF Muma College of Business Practice Center students in private and public forums to extoll the value of developing and maintaining a significant connectivity to the college.

10. Within students (enabled): Limited, at this point there is no forum to share the learnings student and faculty receive from these projects with a wider audience either at the department or college level so it is all "word of mouth" informing that occurs by exception. 


\section{Appendix N: Sports and Entertainment Management Program}

The Sport and Entertainment Management MBA/MS Program (SEM) was created by USF in partnership with Jeff Vinik (owner of Tampa Bay Lightning) and Tod Leiweke (then of Lightning, now with NFL). The idea was to create a dual-adjunct model where the USF SEM faculty would serve as adjunct employees of the Lightning and the Lightning employees could serve as adjunct faculty at USF. The students and faculty of the USF program would learn to understand, refine, and address issues with the Lightning business model and the Lightning would, in turn, give back by providing these learning opportunities for students. The program is funded each year in the low-mid six figures The Lightning provides approximately $30 \%$ in support, $40 \%$ in student funding (15k for 10 students), and a co-branded fundraising golf tournament provides the final $30 \%$

Students in the program receive an MBA in their first year and a MS in Sport and Entertainment Management their second year. The original idea for the program had students "in-residency" for their second year. However, demand for the students by the Lightning and other local firms has been so great that first year students now have part-time jobs in a local firm before beginning their residency. The initial 10 residencies from the Lighting in year 1 have been increased to 27 by reaching out to other organizations locally. These organizations include USF Athletics, Tampa Bay Rays, Seminole Hard Rock Casino, IMG College, Fox Sports, and others.

Other initiatives within SEM include work with Fox Sports University and other outreach to practice through sponsor activation programs. Fox Sports University works to present a problem to a class in January; they visit again in mid-semester and at end of semester. A sample project would include "How to improve television ratings for Lightning games." Students would develop programs and, receive feedback directly from practice; some programs have actually been implemented.

Sponsor activation programs connect students and practice in a consulting relationship. Practice pays a $\$ 7,500$ fee, and students and faculty work with them to solve problems in their organizations.

The Program has an international flavor recognizing the difference in the flow between US sports and international sports. The US arenas are designed to support more revenue generating opportunities due to the interruptions of US sports for commercials and television timeouts. Students are trained to take the best from each model and understand the dynamics of these different environments

The SEM Program has been quite successful in gaining student placements. It has had $100 \%$ placement of each of its graduating classes. As indicated by the program's alumni map (Figure M.1), placements have included many high profile sports teams and media companies. 


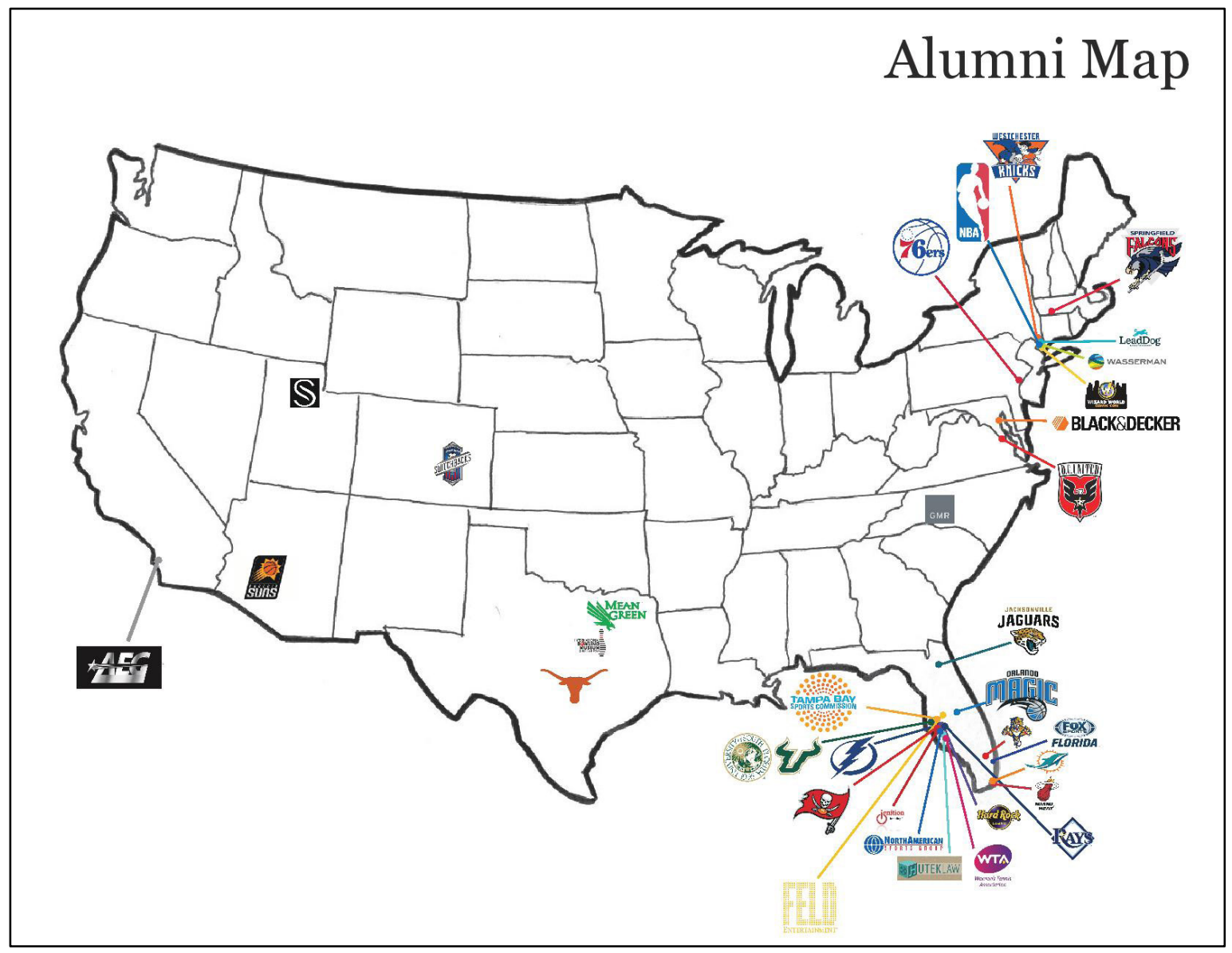

Figure M.1: Alumni placements from Sports and Entertainment Management Program

\section{Outcomes}

The program has been fully operational for only two years. However, the program has had $100 \%$ placement of students upon graduation and, as noted above, has been expanding its partnerships in industry to allow growth in students. Each member of the class of 2016 is currently placed in a residency and each member of the class of 2017 has a part-time job in the industry.

\section{Informing Flows}

The informing flows for this activity are 1-3 and 6-10 as described below (major flows in bold):

1. Institution to student: Student instruction is lecture, guest speaker, and traditional methods. Because of the small size of the program the Faculty receive regular feedback from the students about curriculum and other matters.

2. Institution to research: None

3. Institution to practice: Practice engages the institution for projects, feedback, and mutual training of students. Practice members serve as adjuncts for teaching purposes, and faculty serve as adjunct employees in practice firms.

4. Research to practice (enabled): The applied research that is performed in Fox Sports University programs enables a pathway for future research development. 
Informing Business School

5. Practice to students (enabled): There is a direct interaction between students and practitioners.

6. Research to students (enabled): None

7. Within institution (enabled): There is a direct tie between the SEM program and international programs at the University. This directly bridges the Business School into these programs where there traditionally has not been much overlap.

8. Within research (enabled): None

9. Within practice (enabled): Limited. Fox Sports University and Sponsor Activation programs provide opportunities for various practice members to interact.

10. Within students (enabled): Students are heavily engaged with each other in a variety of activities throughout the program. 


\section{Appendix O: Student Credit Union Branch}

The USF Muma College of Business has formed a partnership with the USF Federal Credit Union (USF-FCU) to open a student-run branch in the Marshall Student Center. There is a three year training program that starts in a student's sophomore year, and this branch is led by six students who are part-time employees. Students come from accounting, finance, marketing, and management. Oversight is provided by the main USF Credit Union but this provides a unique educational opportunity for these students.

\section{Background}

The student-run branch of the USF-FCU was initiated as a collaborative effort between the MCOB and the leadership of the USF-FCU, whose board included three faculty members and an administrator from the MCOB. During the stages when the project was still under discussion, a case study was developed (Will \& Skaggs, 2014). This was used as a basis of discussion between students, faculty, and USF-FCU executives to acquire feedback on the proposal. The branch began the process of bringing in students in 2015 .

\section{Outcomes}

With less than one full semester in operation it is premature to assess the outcomes of the Student Credit Union Branch.

\section{Informing Flows}

The informing flows for this activity are 3, 5, and 10 as described below (major flows in bold):

1. Institution to student: Limited. This is minimized with the external Credit Union having responsibility for oversight. However, institution faculty serves on the board of the credit union and are key in the existence and oversight of this program

2. Institution to research: None

3. Institution to practice: The institution gets direct feedback on training of students and needs for the curriculum working to both develop training and provide qualified students. The direct link of students and practice provides unique insights.

4. Research to practice (enabled): None

5. Practice to students (enabled): There is a direct interaction between students and practitioners.

6. Research to students (enabled): None

7. Within institution (enabled): None

8. Within research (enabled): None

9. Within practice (enabled): None

10. Within students (enabled): The Program is student run, requiring a diverse group of students to function as a team to run this branch. Students come from a variety of majors and backgrounds. 


\section{Appendix P: Student Internships}

The USF Muma College of Business Student Internships are designed to connect organizations with talented students who gain experience in their chosen discipline. Employing interns offers companies the ability to preview potential future employees. Student interns are also well positioned to offer new ideas, solutions, and assistance to the organization on everything from daily tasks to specific projects and programs requiring additional attention ideal for a temporary workforce. Hiring interns also allows the company to find new talent and skills, to make a commitment to the development of the college's best and brightest, and to showcase the organization to the broader student population and community.

\section{Background}

The ideal student internship is paid at a market rate, establishes goals and objectives for the student's work activity, provides appropriate training, and measures progress through feedback and evaluation of student performance. Student interns typically work 20-40 hours a week when the internship is in the summer and 10-20 hours a week when the internship is during a fall or spring semester. Intern programs are defined by each discipline within the USF Muma College of Business (Marketing, Finance, Accounting, and Information Systems), and students are connected to potential student intern employers through a combination of self-selection, interviews, and recommendations by faculty and staff.

The college also offers a Student Intern course for-credit during the academic year that places additional structure and faculty oversight around internships for students that are in a position to utilize that for-credit option in their course selection.

At the beginning of the semester, students attend workshops to enhance their professional business skills. Students review a list of approved internship opportunities by employer, choose opportunities of interest, and then directly apply to the company. The application process routinely involves the completion and submission of a resume, one or more interviews, and, ideally, one or more internship offers.

\section{Outcomes}

The first measureable outcome is the number of employers who see value in the student internship program. Approximately 350 employers have been engaged in the student internship program at the USF Muma College of Business.

A second outcome is the improved probability of a student obtaining a job in his/her field upon graduation. A current NACE Survey on Internships and Co-ops (NACE, 2015) indicates that one student internship increases a student's chance of a job at graduation by $51.7 \%$. At the USF Muma College of Business, approximately $50 \%$ of students without an internship have a job in their discipline within six months of graduation whereas virtually all $(>95 \%)$ student interns have a job in their discipline within six months of graduation.

A third outcome is the opportunity for the employer to identify and pre-select talented students from among their interns for entry level employment. Employers routinely indicate that seeing the student in the work environment with performance against targeted goals and objectives is superior to an interview process alone and increases their confidence in making job offers. Detailed metrics on students hired by employer with which they conducted their internship are not maintained. By exception, PricewaterhouseCoppers $(\mathrm{PwC})$ discloses nationally that $70 \%$ of its entry level (new) employees are hired from its student interns. 
A fourth outcome is student reported assessment of learning associated with the student internships. Currently this evidence is anecdotal with students regularly suggesting that the internship experience was the, or one of the, most valuable learning environments in their college career.

\section{Informing Flows}

The principal informing flows appeared to be 1, 3, and 5 as described below (major flows in bold):

1. Institution to student: The initial student intern workshops, resume preparation, and interview preparation by faculty and staff can make a significant difference in student success in finding appropriate internships that will improve their learning and probability of finding a job upon graduation. To a limited extent by exception student experience in an internship may lead to a conversation with faculty that could influence curriculum as students report new techniques and practices or gaps in their knowledge identified during their internships.

2. Institution to research: None

3. Institution to practice: A two way flow of information occurs with companies identifying entry level employee needs and with faculty and staff identifying and recommending specific students and the best procedures generally to conduct student internship programs.

4. Research to practice (enabled): None

5. Practice to students (enabled): The student is heavily informed by practice through the conduct of the student internship. In the best internships, employers invest in student growth and success with training, objective setting, evaluation, and feedback. Frequently, students are trained in the role, the organization, and the broader discipline itself. Often a supervisor and/or mentor is assigned to each student, leading to informal and formal counseling and advising on the work to be performed and on the most effective approach for success in the organization. Students also frequently inform the business. Students come with a different perspective and new ideas that may have merit. They also are often digitally and socially savvy in ways that can make a contribution to the organization and business teams with whom they work.

6. Research to students (enabled): None

7. Within institution (enabled): Limited. With the expansion and centralization of the internship program, greater collaboration between departments in locating and filling internship spots is anticipated.

\section{Within research (enabled): None}

9. Within practice (enabled): Limited. Local employers often cite positive experiences with USF Muma College of Business student interns in private and public forums to extoll the value of developing and maintaining a significant connectivity to the college.

10. Within students (enabled): Limited. Students routinely share their experiences at various employers and often influence the choices of other students as to the desirable employers and jobs in the market. An excellent intern experience can lead to significantly more interest in an employer's job fair on campus as can a preponderance of poor experiences on the part of multiple students. 


\section{Appendix Q: Student Managed Investment Fund}

The USF Muma College of Business Student Managed Investment Fund (SMIF) manages in excess of $\$ 400,000$ raised specifically for the purpose of student education. Investment decisions are made based on student recommendations to an advisory board of up to 60 individuals from 40 firms who engage students at stock pitches, in other business activities, and in a more formal classroom setting.

The classes surrounding the SMIF are Applied Securities Analysis (undergraduate) and Advanced Investments (undergraduate and graduate). These classes serve as an intersection for fundraising (development), community engagement, alumni engagement, and scholarship.

\section{Outcomes}

Quantitatively the SMIF outperforms its benchmark, the S\&P 500 on a routine basis. Through $9 / 30 / 2015$ the active portfolio had outperformed the S\&P500 by 200bp. The SMIF has nearly $100 \%$ placement (or continuation of education) at graduation at salaries more than $50 \%$ higher than those of other finance majors at USF. The program engages over 60 professionals from 40 firms with the University on a consistent basis throughout the year to achieve these outcomes.

\section{Informing Flows}

The informing flows for this activity are 1, 3, 5-7, and 10 as described below:

1. Institution to student: Students interact with the Faculty Director for lecture, classroom, and rigorous feedback.

2. Institution to research: Limited. This unique model of a SMIF is subject to several research activities.

3. Institution to practice: The program accesses professionals, modifies curriculum based on their input, discusses student training and key events in the industry and the SMIF portfolio, and adjusts training, actions accordingly. Practitioners are routinely invited into classroom and students engage multiple investment firms via scheduled video-conference calls

4. Research to practice (enabled): Limited. Researchers are actively engaged with practitioners in formal and informal settings. Both the Faculty Director and Department Chair regularly screen research ideas and thoughts in this setting.

5. Practice to students (enabled): There is a direct interaction in pitches and formal and informal settings between students and practitioners. Professionals participate in both the classroom and specific events.

6. Research to students (enabled): The USF Muma College of Business supports undergraduate research, and certain Honors College students have explored and are actively doing research on topics inspired by and supported by the SMIF.

7. Within institution (enabled): The SMIF requires intensive cross-discipline training for the students. The Business Writing center, development, marketing, and administration are involved in the SMIF.

8. Within research (enabled): None

9. Within practice (enabled): Limited. The SMIF Board is composed of professionals from various industries, and meetings provide a venue for interaction between them. 
10. Within students (enabled): Students work with all classmates on projects. The SMIF classes are comprised of two undergraduate and one graduate class which all intersect at various times. Students are responsible for recruiting other students by classroom visits and formal mixer functions which they run. 


\section{Appendix R: Symposium of Student Research}

The Symposium of Business Student Research is a recent edition to the informing practices of the USF Muma College of Business and had only undergone one iteration at the time of this article. The Symposium was designed as an annual event to showcase student conducted research. Students in the USF Muma College of Business were given the opportunity to voluntarily submit their research for display using a poster board presentation in the public atrium of the Muma College of Business.

Student research was accepted from Undergraduate, Masters, and Ph.D. students. Research was judged by a panel of four members of the college's research active faculty. Awards were given to three students on the basis of research excellence.

The USF Muma College of Business Honors Program lead the initiative with co-sponsorship from the college's Center for Analytics and Creativity.

\section{Background}

The Symposium grew out of a desire on the part of the Honor's Program to establish an outlet that recognized and rewarded the significant student research activities in the Muma College of Business. The venue was chosen for its relatively high level of visibility within the college (the atrium) and the probability that foot traffic would increase the exposure of the students and their posters to a broad audience of fellow students and faculty.

\section{Outcomes}

The first Symposium lead to eight undergraduate, three masters, and six Ph.D. research poster presentations, which was considered a relative minority of the actual research underway in the college. Foot traffic lead to the research being viewed by several dozen interested students and faculty.

Presenters reported a generally positive experience gained describing research in a poster and presentation format in a manner that was similar to that required of many academic conferences.

Observers and faculty judges were impressed with the variety and quality of research underway although the volume of submissions was considered low relative to the amount of student research underway college-wide.

Additional desired outcomes in future symposia could include a fast-track to publication selection process with the Muma Business or Case Reviews, additional awards for multiple categories, broader participation of student and faculty observers, and possible introduction of business/practitioner observation and interaction with the student presentations (perhaps starting with the various Muma College of Business industry advisory council members).

\section{Informing Flows}

The principal informing flows appeared to be 1,2,6, 7, and 10 as described below (major flows in bold):

1. Institution to student: Strong informing flows from faculty advisors and Symposium judges to students on the conduct and rigor of research presented was evident. Student researchers informing faculty and student peers was also evident.

2. Institution to research: Several examples of high quality research that was or would be submitted to academic conferences and journals was evident in the Symposium. Litera- 
ture reviews, research questions, and research methodologies were all informed by the body of academic research in the student's area of interest.

3. Institution to practice: Low. Some of the research had implication for practice but the Symposium was not a venue (at that time) for enabling the informing of practice.

4. Research to practice (enabled): None

5. Practice to students (enabled): Limited. Some of the research had implication for practice but the Symposium was not a venue (at that time) for enabling the informing of practice.

6. Research to students (enabled): Same as \#2.

7. Within institution (enabled): Limited. Informing across disciplines within the USF Muma College of Business on the current state of research (for the research presented) was observed.

8. Within research (enabled): None

9. Within practice (enabled): None

10. Within students (enabled): Limited. Several dozen students were observed reviewing and discussing student research through the conduct of the Symposium. 


\section{Appendix S: 25 under 25 Program}

The 25 Under 25 program recognizes outstanding undergraduate students from the USF Muma College of Business. Students selected for this honor are individuals who are under 25 years of age and have demonstrated excellence in at least two of the following four areas: scholarship, professional development, leadership, and community/campus service. Students self-nominate and fill out an application that includes a background essay and letters of recommendation.

The goal of this program is to highlight the positive impact students have on campus as well as in the regional community and to recognize their leadership and academic achievements. Students are selected by a select group of professionals who read and score the application packages.

\section{Outcomes}

The principal outcomes of the 25 under 25 program, which has been in place since academic year 2009-2010, have been to:

- Provide student participants with additional training in business skills and marketing themselves.

- Substantially raise the profile of USF students within the local business community, with 25 under 25 presentations being featured at Advisory Board meetings and Muma College of Business events.

The 25 under 25 program and events have also drawn sponsorship from T. Rowe Price, a major investment firm.

\section{Informing Flows}

The informing flows for this activity are 1, 3, 5, 9, and 10 as described below (major flows in bold):

1. Institution to student: Students complete a package and essays are reviewed by the Business Communications department. Feedback on writing and style are given to students.

2. Institution to research: None

3. Institution to practice: The institution interacts with practice to provide reviewers, and there are external functions with practice for students that are selected. Practice becomes familiar with both student work and student backgrounds.

4. Research to practice (enabled): None

5. Practice to students (enabled): There is a direct interaction between students and practitioners

6. Research to students (enabled): None

7. Within institution (enabled): None

8. Within research (enabled): None.

9. Within practice (enabled): Limited. There is interaction among a diverse group of practitioners who select students

10. Within students (enabled): Limited. A diverse group of students is selected and attends functions once selected. 


\section{Biographies}

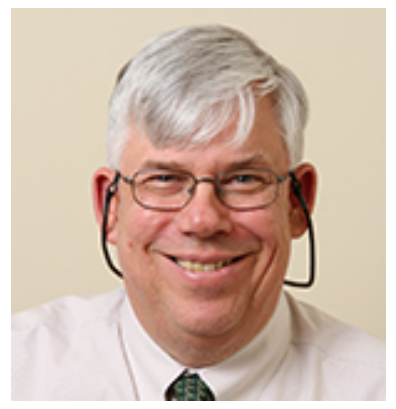

Grandon Gill is a professor in the Information Systems and Decision Sciences department of the University of South Florida. He is also the Academic Director of the Doctor of Business Administration program at the Muma College of Business. He is the Associate Editor-in-Chief of Informing Science: The International Journal of an Emerging Transdiscipline and the Journal of IT Education: Discussion Cases, also serving as a Governor and Fellow of the Informing Science Institute. In 2014, he was the inaugural recipient of the Zbigniew Gackowski Award for contributions to informing science research.

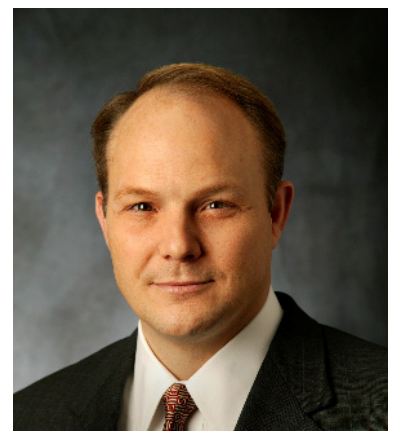

Matt Mullarkey is the Director of the Doctor of Business Administration Program at the USF MUMA College of Business and a Visiting Professor in the Information Systems and Decision Sciences department at the University of South Florida. He holds a Ph.D. in Business Administration (Information Systems) from USF, a BS, Engineering, from the United States Military Academy, an MS, Systems Management, from the University of Southern California, and an MBA from the Moore Business School, University of South Carolina. Matt has more than 25 years of experience as President, CEO, COO, and SVP in the automotive, applied materials, and medical device industries with $\mathrm{P} \& \mathrm{~L}$ responsibilities globally. His principal research interest are the impact of social networking in and between organizations, monetization of companies' data streams, and applying the case method to MIS and MBA education. He is an editor for the Journal of IT Education: Discussion Cases.

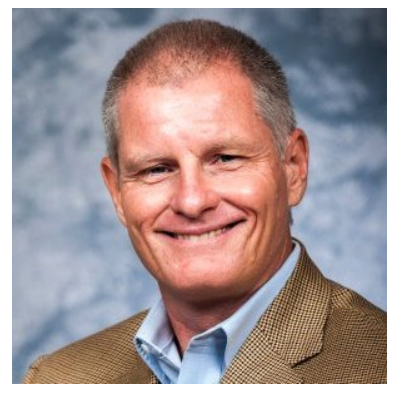

Joseph E. Mohr has a Ph.D in Finance from the University of South Florida, where he served as an Visiting Assitant Professor of finance and Director of the Student Managed Investment Fund. He also holds anMBA from the University of Chicago. He currently serves as Chief Investment Officer of Rudd International. Prior to receiving his Ph.D, he worked more than 20 years in consulting, finance, and governance. He has served as CFO of public and private firms in financial services, manufacturing, and oil and gas. Joe has also served as adjunct faculty in finance at the University of Tampa for many years.

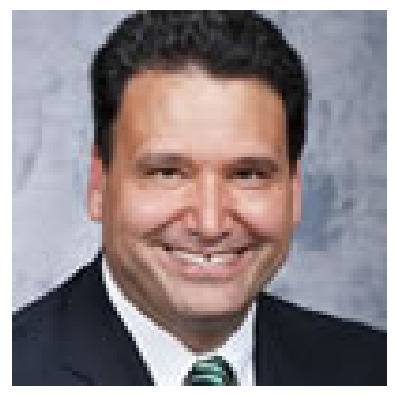

Moez Limayem is dean of the USF Muma College of Business, joining USF in 2012 from the Sam M. Walton College of Business at the University of Arkansas, where he served simultaneously as the associate dean for research and graduate programs, the executive director of the Information Technology Research Institute and the Radio Frequency Identification Center, and the Edwin \& Karlee Bradberry Chair in Information Systems. Limayem was responsible for all the graduate business programs and executive education programs and also supervised 11 outreach and research centers. Limayem worked in the private sector as a systems analyst and computing consultant before receiving his MBA and PhD in business administration from the University of Minnesota. Since 1992, he has served as an international expert in IT for UNESCO. He has taught at universities across the globe: he taught at the University of Minnesota, Laval University in Canada, City University of Hong Kong, and Lausanne University in Switzerland, as well as the University of Arkansas. 